University of South Florida

DIGITAL COMMONS Digital Commons @ University of @ UNIVERSITY OF SOUTH FLORIDA South Florida

$11-1-2009$

\title{
Routes to New Networks: A Guide to Social Media for the Public Transportation Industry
}

CUTR

Follow this and additional works at: https://digitalcommons.usf.edu/cutr_nctr

\section{Recommended Citation}

"Routes to New Networks: A Guide to Social Media for the Public Transportation Industry," National Center for Transit Research (NCTR) Report No. CUTR-NCTR-RR-2009-09, Center for Urban Transportation Research, University of South Florida, 2009.

DOI: https://doi.org/10.5038/CUTR-NCTR-RR-2009-09

Available at: https://scholarcommons.usf.edu/cutr_nctr/148

This Technical Report is brought to you for free and open access by the National Center for Transit Research (NCTR) Archive (2000-2020) at Digital Commons @ University of South Florida. It has been accepted for inclusion in Research Reports by an authorized administrator of Digital Commons @ University of South Florida. For more information, please contact digitalcommons@usf.edu. 


\title{
Routes to New Networks
}

\author{
A Guide to Social Media for the \\ Public Transportation Industry
}

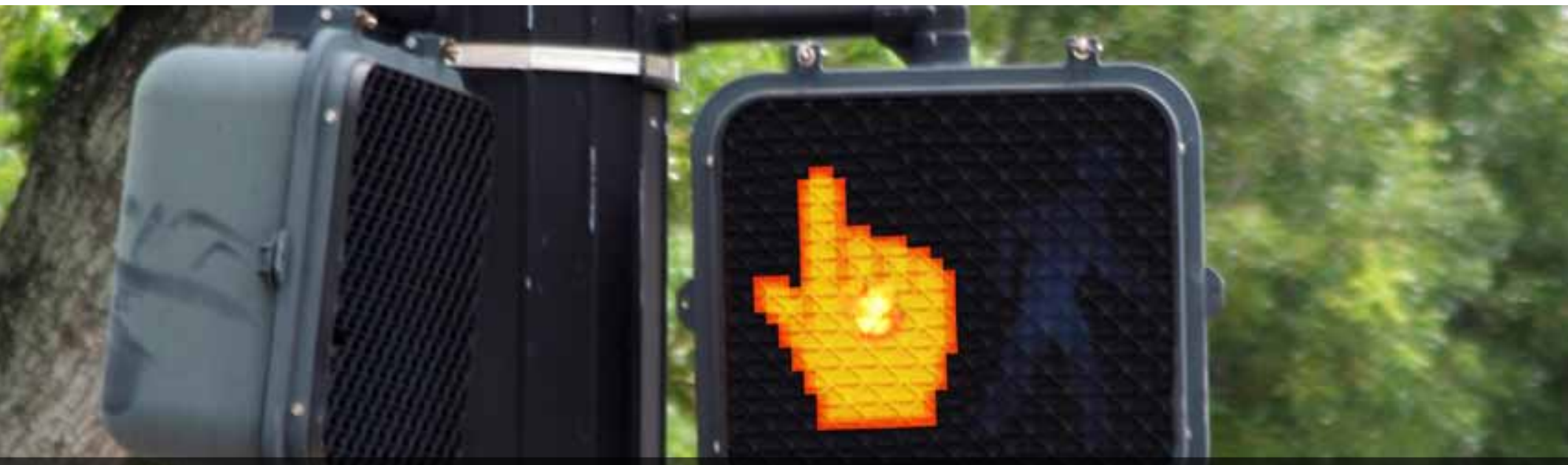

\section{Final Report}

- a November 2009

Prepared for

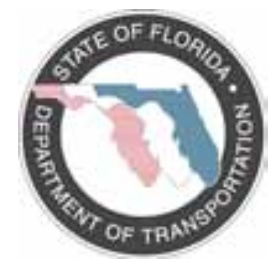

Florida Department of Transportation BD549-53

\section{Prepared by}

National Center for Transit Research Center for Urban Transportation Research University of South Florida 4202 E. Fowler Avenue, CUT 100 Tampa, FL 33620-5375

(813) 974-3120

http: / / www.nctr.usf.edu
Kidd Transportation Group 2074 Centre Pointe Blvd

Tallahassee, FL 32308

(850) 878-6663

http: / / www. kiddtransportationgroup.com 


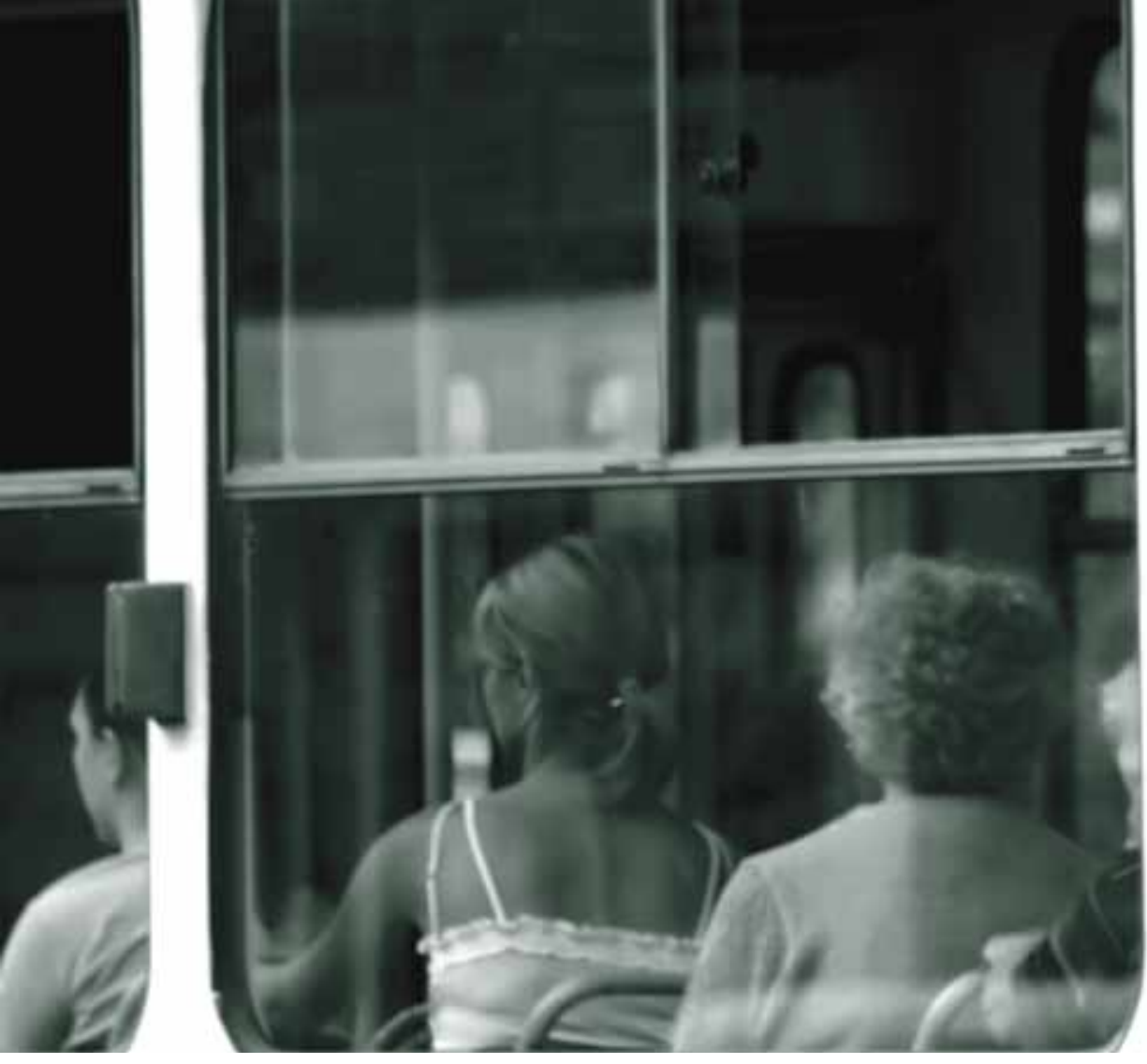

Florida Department of Transportation Project Manager:

Elizabeth Stutts, Grants Program Administrator

Principal Investigators:

William P. Morris, Senior Research Associate

Robert J. Gregg, Director, Transit Management and Innovation

In Collaboration with:

Kidd Transportation Group

Kelly Robertson, Public Relations Director

Justin Hancock, Social Media Maverick

Rebecca Kuitems, Communications Associate

Jeremy Spinks, Designer

Project Staff:

Mark Mistretta, Research Associate

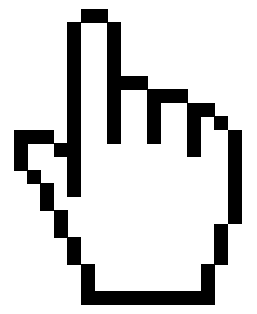

Note: Routes to New Networks is a guide book that was prepared based on a study originally entitled, "Utilizing Information Technology in Innovative Marketing Approaches for Public Transportation," sponsored by the Florida Department of Transportation in support of the National Center for Transit Research. 


\section{Routes to New Networks}

\section{A Guide to Social Media for the Public Transportation Industry}

$\begin{array}{lr}\text { Overview } & 4 \\ \text { Social Networks } & 7 \\ \text { Written Blogs } & 27 \\ \text { Audio/Video Blogs } & 37 \\ \text { Microblogs } & 41 \\ \text { Photo Sharing } & 46 \\ \text { Video Sharing } & 51 \\ \text { User-Generated Content } & 55 \\ \text { Mobile Web } & 62 \\ \text { Social Media Wrap-up } & 64\end{array}$




\section{Social Media An Introduction}

Each and every day, social media tools change the way that organizations interact with their users. Not only do these new platforms offer more personal one-on-one interaction than traditional mediums, but they represent the essence of niche marketing. It is undeniable that social media is all the buzz. For some, utilizing new media tools may come as second nature. For others, however, entering the world of social media means taking a giant leap into the world of online communications.

One thing is certain - social media platforms are allowing a new opportunity for transportation providers to directly communicate with their target audiences. While it might be new and unfamiliar territory, transit agencies should embrace it as another tool in the toolbox. Your marketing platform might currently be armed with advertising, public relations, and web components. Today, we invite your organization to take a closer look at what social media outlets can do for you. We want your organization to gain a better understanding of how these online cost-effective tools can assist with your communication efforts, adding depth to your current approach.

So what is social media? In aggregate, social media is a group of websites that provide different and unique ways to have an online conversation. In this arena, consumers generate the news, trends, and topics. What are the perks? This is where many of your target audiences are already communicating. In fact, maybe they're already talking about you, but you just aren't listening. You have a direct access to them. Plus riders, residents, experts, and brand warriors alike can help spread your message.

Both industry giants and small entities alike have used social media with great success. Many are citing sales increases as a result of recent online activity. What does this mean for transit systems? Transit systems have many new networks to foster relationships with current riders while targeting potential users, advocates, and your general public. By following the guidelines presented in this handbook, your organization will better understand how to get plugged in. Internet users are joining 
social networks at an incredible rate and they're looking to interact. It's time to join the conversation.

Social media tools include everything from blogs and micro-blogs (Twitter) to networking sites (Facebook, Myspace, LinkdIn) and video sharing (YouTube). An appropriate mix of social media platforms are recommended based upon your goals, target audience, and desired action. Generally speaking, social media tools can be used to achieve the following:

- Build awareness

- Gain instant feedback

- Foster relationships

- Become an expert

- Communicate directly with loyal fans

- Incite action

Today, utilization of many social media tools is seen as an added-value opportunity. As society transforms, these tools will quickly become a necessity for those looking to communicate. It will be imperative that you are equipped with the knowledge and ability to meet your customers where they are conversing. Gone are the days when having a Website was the extent of your online presence. Gone are the times when your only microphone was a daily newspaper and nightly television broadcast.

Social media tools are ever-evolving, as each day new platforms are created. As with anything unfamiliar, at first these new tools and guidelines will be overwhelming. (It's alright if your head is spinning.) Begin with listening, then get plugged in and start talking. Experience is truly the best teacher.

\section{Communication is moving in this direction - with or with- out your organization. Get onboard.}

\section{Key Points To Consider:}

Social Media is running and active 24 hours a day, seven days a week around the world. Don't let this scare you. But it means that conversations can be happening at any time day or night. Stay alert and monitor often.

You must still consider messaging when distributing information via these social media tools. Anything you say can be re-posted by anyone or consumed by more traditional media outlets (print, tv, radio).

Content must always resonate with your audience. What can you provide that would be of value? 
Social media is an investment. While nearly all of the sites are free to use, maintaining these accounts takes time.

\section{Which Tools Should I Be Using?}

When selecting social media tools, ask two questions:

1) Who is my target audience and what tools are they using?

2) What type of information do I want to communicate?

The following is a broad overview of the most common social media tools. In no way is it inclusive of every available tool. Rather, specific online applications have been highlighted which present the highest value and use for the transportation industry. While this study is not endorsing one application over another, this guidebook will prove helpful when trying to determine your strategy for implementation. 
upcoming event, broadcast route changes, or even announce ridership numbers.

Vanity $U R L$ - If your organization has enough fans, creation of a personalized Facebook web address using your organization's name is allowed, such as Facebook.com/(insert organization name). This makes it easier for consumers to recall your organization's page name.

Report - Click the report button to inform Facebook's administration team of disruptive or harassing messages and comments that violate the Facebook Terms of Use.

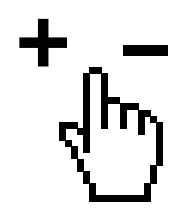

\section{Benefits}

- 2-way conversation with customer

- Audience seeks out your message, which means no competition with other advertising "clutter"

- Easily accessible

- Can serve as online social media "hub"

- Status updates are seen instantaneously

\section{Drawbacks}

- Can be difficult and time-consuming to accumulate "fans"

- Monitoring is difficult due to privacy settings on individual accounts

- No way to prevent the creation of unofficial groups related to your organization but not officially endorsed by your organization

\section{First Step: Fan Pages vs. Groups}

Facebook allows businesses two options when creating a profile: Fan Pages or Group Pages. Both options allow great user interaction. However, for the purposes of transportation, Fan Pages allow for greater customization and include tracking tools, which would prove beneficial.

\section{How to decide Fan Page or Group? Let us help:}

\section{Fan Pages}

- Page "wall" allows for interaction between the fans and the business if desired

- Page activity (photo uploads, etc.) is automatically seen by fans

- Page is customizable

- Allows page creators to remain anonymous

- Pages can benefit from social ads that publicize the fan connection between a Page and a specific user

- Fan pages over 100 users may create custom/vanity URLs

- Pages have monitoring capabilities
Group Pages

- Administrator's information is public

- Administrators control who joins

- Groups under 5,000 members can send email blasts to members 


\section{Monitoring - Insight:}

Facebook offers the monitoring tool Insight with every Fan Page. Insight gathers information regarding fan demographics and location. It also shows page views, new fans, media consumption, and much more on a day-by-day basis.

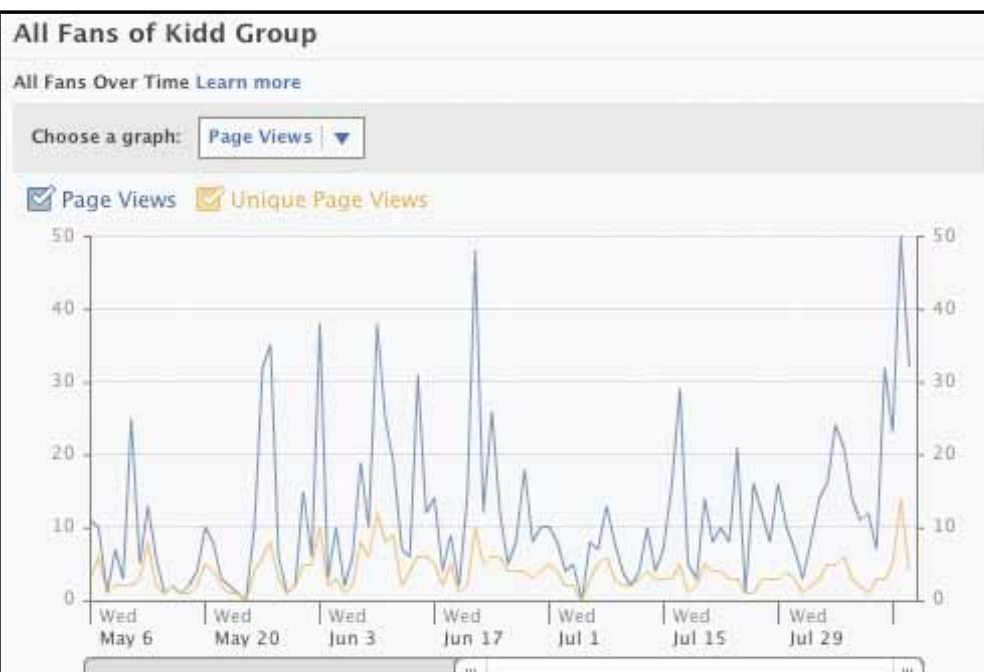

\section{4}

\begin{tabular}{|c|c|c|c|c|c|c|}
\hline & Male $F$ & Female & & Male & Female & \\
\hline & & & & $27 \%$ & $72 \%$ & \\
\hline & & & $13-17$ & $1 \%$ & $3 \%$ & $4 \%$ \\
\hline & & & $18-24$ & $8 \%$ & $48 \%$ & $56 \%$ \\
\hline & & & $25-34$ & $6 \%$ & $13 \%$ & $19 \%$ \\
\hline & & & $35-44$ & $6 \%$ & $8 \%$ & $14 \%$ \\
\hline & 4 & & $45-54$ & $6 \%$ & $1 \%$ & $7 \%$ \\
\hline & $\|$ & & $55+$ & $1 \%$ & $1 \%$ & $2 \%$ \\
\hline Top Countries & & Top Cities & & Top Langua & ages: & \\
\hline $\begin{array}{l}\text { United } \\
\text { States }\end{array}$ & 139 & Tallahassee & 37 & $\begin{array}{l}\text { English } \\
\text { (US) }\end{array}$ & & 140 \\
\hline
\end{tabular}

Figure 1: a snapshot of an insight

report:

\section{How Can Transit Systems and Commuter Services Organizations Use Facebook?}

- Raise awareness of your organization

$\sim$ Educate potential riders and stakeholders

$\sim$ Broadcast information on upcoming events

- Foster relationships with current customers

$\sim$ Offer online contests

$\sim$ Provide valuable route information / system-wide updates

- Humanize your organization's brand

$\sim$ Send updates on employee milestones (awards and honors, no-

table employee achievements outside work, company events and sponsorships, etc.)

- Use as a central online hub

$\sim$ Link up all social media accounts such that Facebook acts as your organization's social media website 


\section{Example: Bay Town Trolley}

The Bay Town Trolley is the public transportation system in Bay County, Fla. utilizing the Facebook Fan Page as a way to connect with area residents and riders. Specifically, they send relevant status updates, allow for the sharing of ridership stories on their wall, and upload event photos.

http://www.baytowntrolley.org/facebook

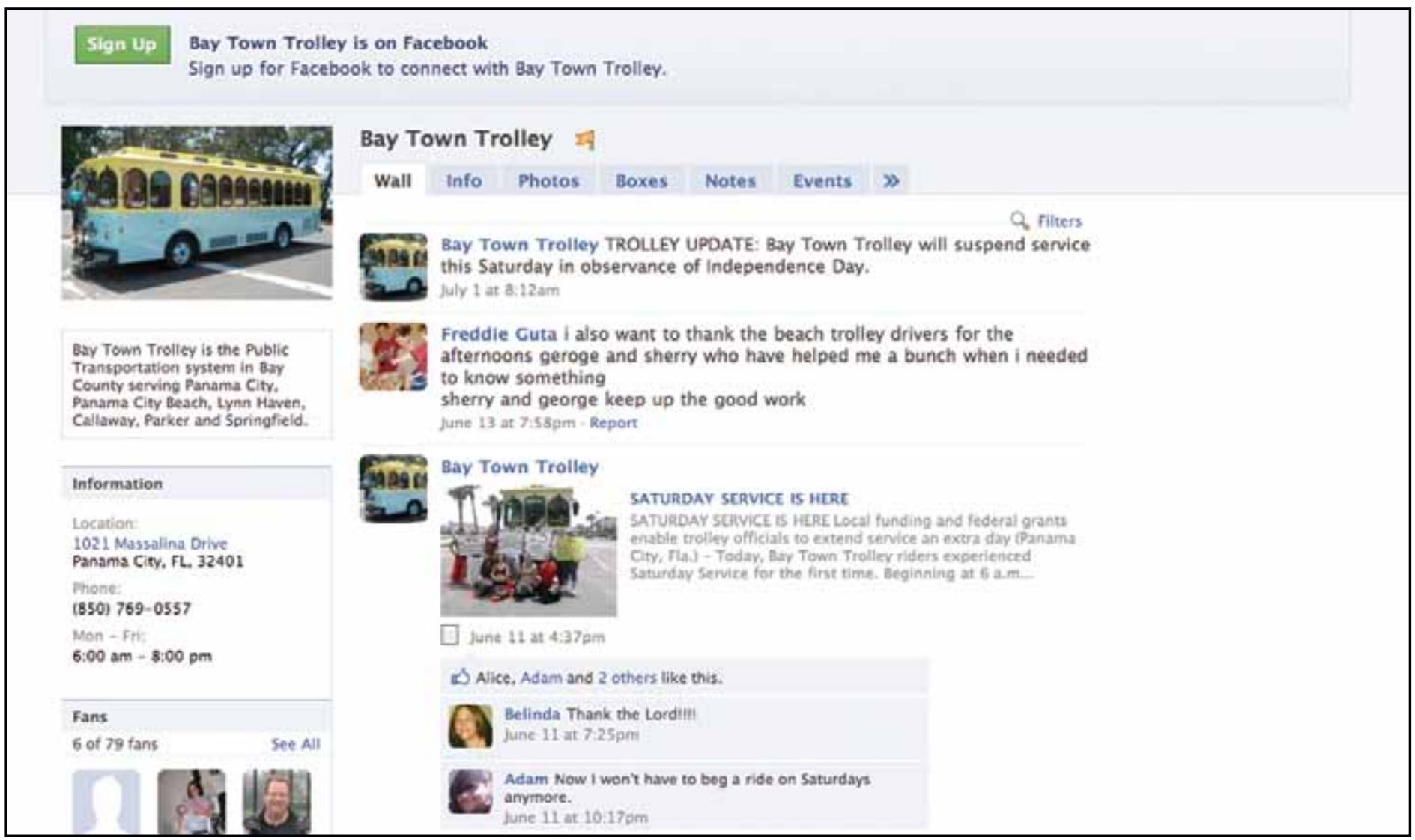

Figure 2: Bay Town Trolley on Facebook 


\section{Example: Public Transportation}

This is a Facebook Fan Page dedicated to encouraging individuals to use the local public transpiration systems. By posting information about new transportation systems as well as tips, photos and links, this profile is able to project the image of public transit use as a trend.

http: / / www.facebook.com/s.php? q= publictransportation\&sid $=111957000$

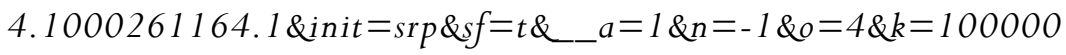

000020\#/pages / Anytown-USA / Public-Transportation

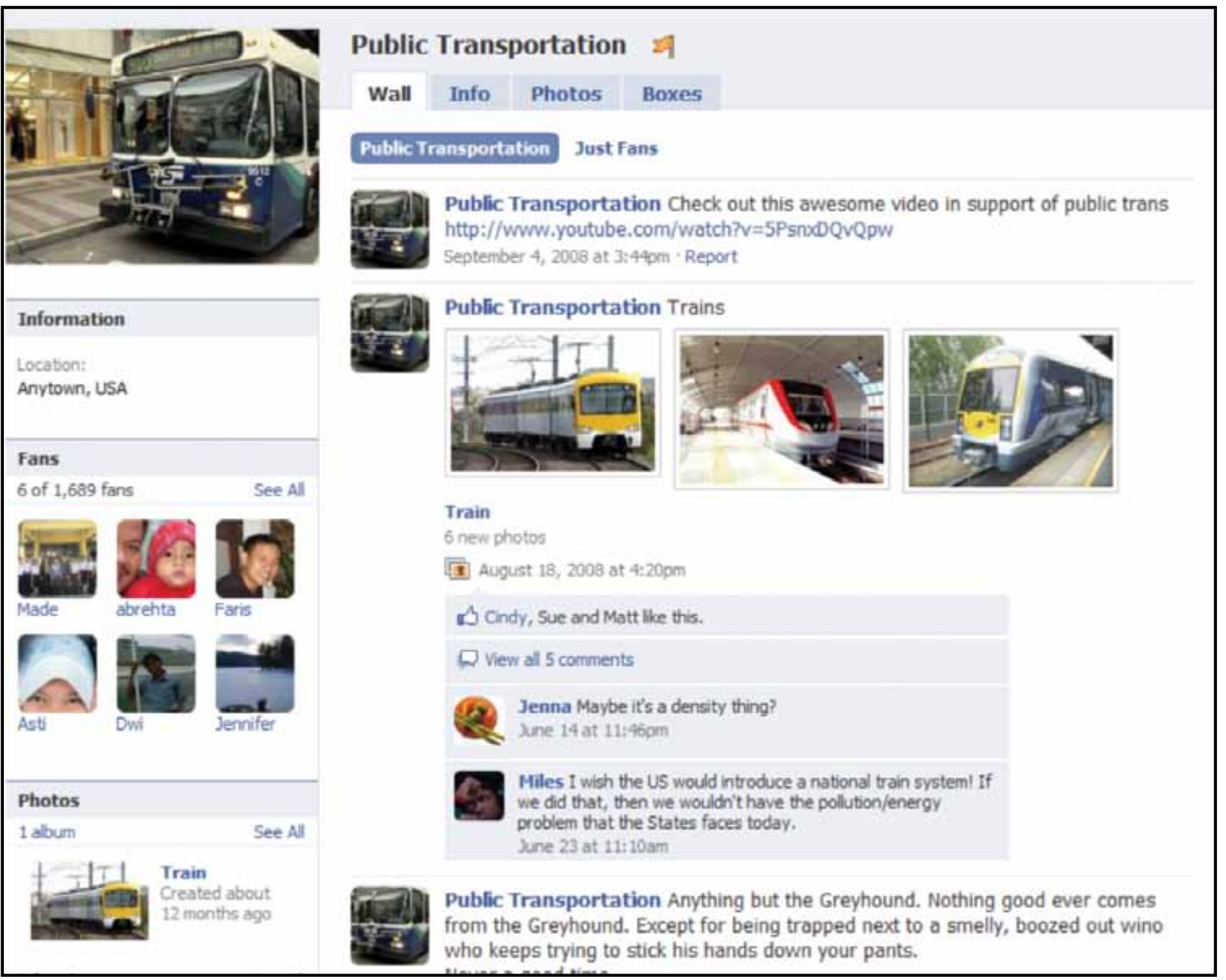

Figure 3: Public Transportation Fan

page on Facebook 


\section{Example: Commuter Services of Pennsylvania}

Commuter services of Pennsylvania works to reduce traffic and improve air quality. Their goal is to help commuters find alternatives to driving alone to work. Through their Facebook Fan Page they keep users updated on traffic conditions that may affect their carpool's commute.

http: / / www.facebook.com/pages / York-PA / Commuter-Services-Of-Pennsylvan ia $/ 96621387693 ? \mathrm{ref}=$ search\&sid=1432321661.476412279..1

\section{Sign Up Commuter Services of Pennsylvania is on Facebook}

Sign up for Facebook to connect with Commuter Services Of Pennsylvania.

\section{COMMUTER SERVICES \\ OF PENNSYLVANIA}

Commuter Services is a tree service working to reduce traffic and improve air quality. We help commuters find alternatives to driving alone to work. We currently serve Adams, Berks, Cumberland, Dauphin, Lancaster, Lebanon, Perry and York Counties.

\section{Information}

Location

2951 Whiteford Road - Suite 201

York, PA, 17402

Phone:

1.866 .579 .7433

\section{Fans}

6 of 111 fans See All

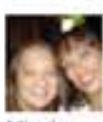

Mindy

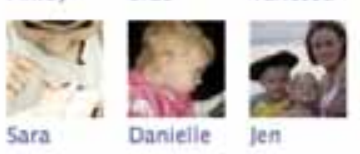

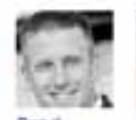

Brad

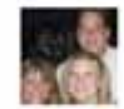

Vanessa

len

\section{Commuter Services Of Pennsylvania 2 月}

Wall Info Photos Discussions Reviews Events $\gg$

\section{Q Filters}

Commuter Services Of Pennsylvania Traveling on 1-83 South near scheduled for Thursday, Nov. 5 Bridge inspection crews have scheduled routine follow-up inspection activities Thursday, Nov. 5 , on the John Harris Memorial Bridge that carries 1-83 over the Susquehanna River in Harrisburg, Dauphin County.

November 4 at $6: 23 \mathrm{pm}$

Jit Commuter Services of Pennsylvania Scheduled field

Jita work will require daylight lane restrictions between 9:00 a.m. $-3: 00$ p.m., weather permitting, in the northbound right lane and shoulder of the I- 83 South Bridge. On average more than 123,000 vehicles travel $1-83$ across the Susquehanna River each day.

November 4 at $6.23 \mathrm{pm}$

deze Commuter Services Of Pennsylvania Bridge inspectors will be removing data collection equipment that was installed on the bridge last week. PennDOT reminds motorists to adjust their schedules or allow extra time in their travel plans in order to avoid delays. Please remember to slow down, drive cautiously and watch for slowing and/or queued traffic in the vicinity of the work zone for vour safety as well as the safety of the inspection crew.

November 4 at $6.24 \mathrm{pm}$

Commuter Services of Pennsylvania With the holiday season now less JTER SE than 8 weeks away, and gas prices up almost 40 cents per gallon over V NS Y L what they were just a month ago, NOW is the time to think about saving money! We can help you find a carpool or transit route that suits your daily work commute. Check out our website for ridematch info or call 1.866.579.RIDE (toll-free) to start saving this week! November 1 at $5.07 \mathrm{pm}$

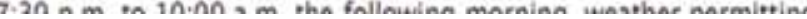

Figure 4: Commuter Services of

Pennsylvania Fan page on Facebook 


\section{How to Set Up a Facebook Page}

To start a Facebook Fan Page first define your organization, your definition might be government, public service, travel, etc. Following this, Facebook setup will take your organization through a series of profile questions. When the page is first created it is not immediately published for public viewing. This gives your organization the chance to upload images and add any applications necessary. Once finished customizing, your organization's page can be launched. It's a good idea to launch internally first, so your organization's fan page has existing fans and can be populated with content.

For more information / full details on Fan Page setup visit:

http: / / www.facebook.com / help.php?page $=906$

\section{Facebook Advertising}

Facebook offers a unique advertising feature, which allows businesses to target specific segments of the population. These ads appear in the form of web banners and should be action-oriented messages, which elicit a "click" from users. Facebook has created a method for advertisers which target specific individuals based on their age, demographic info, personal likes and dislikes. How? Advertisers select a grouping of keywords, ages or demographics, which resonate with their target audience.

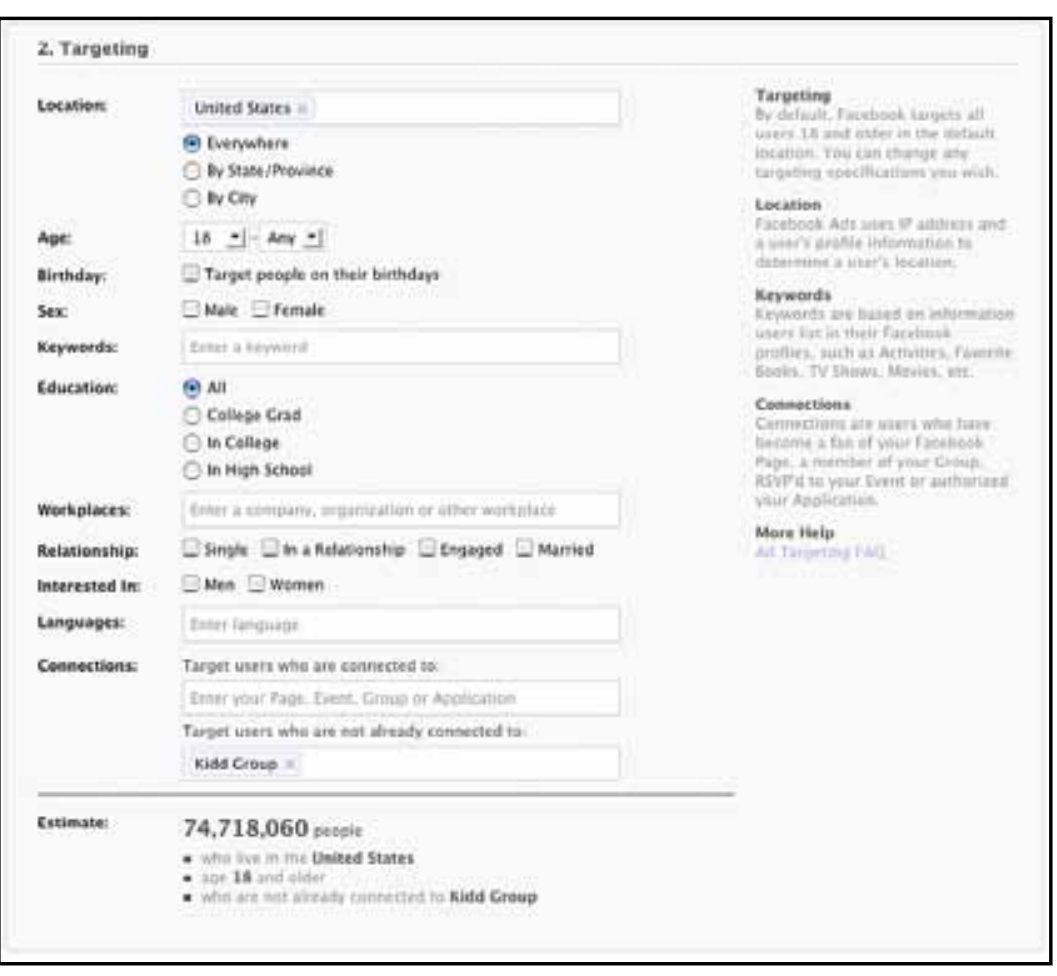

For instance, businesses can target only those users who live in the Panama City area - over the age of 50 - who express interest in public transit. And the list goes on. This means your organization's chances of reaching users with information relevant to them significantly increases. The key to making Facebook ads work is the content.

Facebook offers some suggested tips for creating ads here: http: / / www.facebook.com/ads / best_practices.php/

Figure 5:Targeting Ads on

Facebook 


\section{MYSPACE $^{\mathrm{TM}}$}

\section{What is MySpace?}

While MySpace has lost its place at the top of the social networking world, it can still be an important part of a social media campaign. MySpace is the second largest social networking website in the United States with just over 70 million users. MySpace allows users to create and customize personal pages to a much larger degree than rival Facebook. MySpace's demographic range skews younger than that of Facebook (specifically toward the 13-17 age group).

\section{Key Terms}

Bulletins - Posts that are posted on to a bulletin board for a user's entire friends list to see. Bulletins are deleted after ten days.

Groups - The groups feature allows a group of users to share a common page and message board. Groups can be created by anyone, and the moderator of the group can choose to approve or deny requests to join.

MySpace Video - is a service similar to YouTube ${ }^{\mathrm{TM}}$. Unlike YouTube, MySpace Video has focused on providing television content to viewers as well as user created videos.

MySpace Mobile - Users can log onto MySpace via their phone by navigating to m.myspace.com. On the mobile website users can send and receive messages, leave comments, update mood and status, browse photos, look at profiles, add new friends and read and post blogs.

MySpace News - MySpace News displays news from RSS feeds that users submit. It also allows users to rank each news story by voting for it. The more votes a story gets, the higher the story moves up the page.

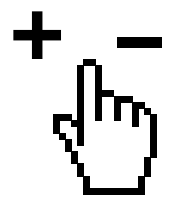

\section{Benefits}

- 2-way conversation with customer

- Reaches young, hard-to-reach age group

- Allows for more personalization on pages with use of color schemes and background templates

\section{Drawbacks}

- Allows customers to express discontent

- Others can view customers discontent

- Current perception that MySpace is for youth only

- Difficult and time-consuming to build friend base 


\section{Monitoring}

This platform offers MySpace Search for monitoring purposes. Here, users can type a keyword into the search engine and search all of MySpace. This monitoring is limited in that it doesn't allow for targeted strategic searches.

\section{How Can Transit Systems and Commuter Services Organiza- tions Use MySpace?}

- Create awareness amongst younger demographic

$\sim$ Coordinate contests / promotions to capture attention

$\sim$ Organize local events and rallies

$\sim$ Broadcast important system-wide information

\section{Example: Island Transit Services}

The local transit system located in Oak Harbor, Washington is using MySpace to help save the system from going under. The profile helps increase ridership, bring in supporters, and organize rallies and events. http: / / www.myspace.com/484318783

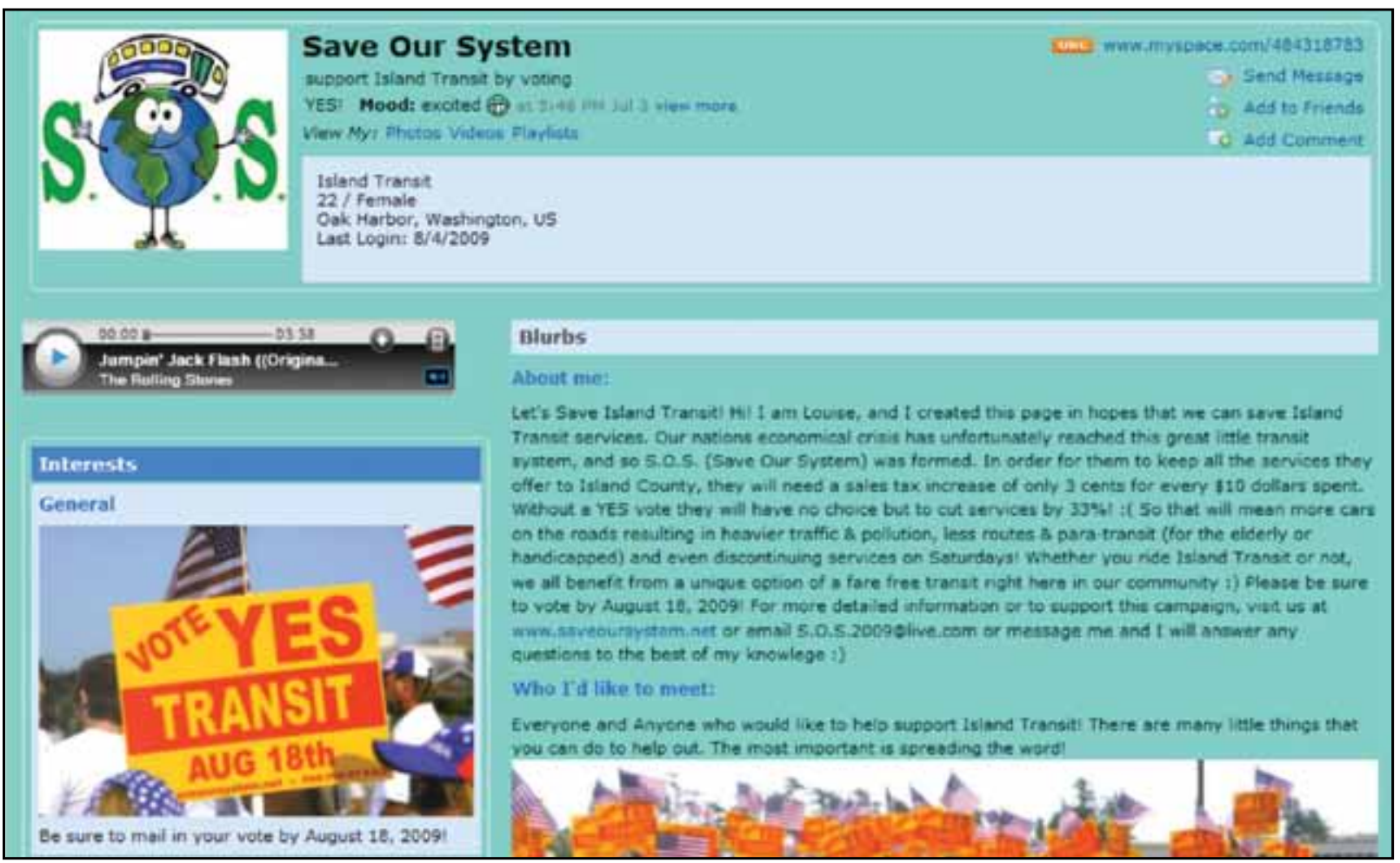

Figure 6: Island Transit Services on

MySpace 


\section{How to Set Up a MySpace Account}

To set up a MySpace account your organization must choose a user name, a URL for your profile, and upload content such as photos, video and music. For more information visit:

http:/ / faq.myspace.com/app/answers/detail/a_id/298/session/

L3NpZC8yVFROVGhGag\%3D\%3D 


\section{NING ${ }^{\circledR}$}

\section{What is Ning?}

Ning allows users to create their own customized social networks. The purpose of Ning is to create niche social networks with members connected by a common interest. This can be anything from an "I love public transportation" network to a "transportation marketing network." Setup of the basic Ning social network is free and offers a place for members to communicate online with one another.

\section{Key Terms}

Visual Design - Ning provides 50 different themes for users to choose for their social network as well as the option for users to create their own theme with custom CSS (Cascading Style Sheet).

Unique Member Profiles - A network's creator can choose their own profile questions for incoming members. Members are also allowed to customize their profile page with their own design, choice of widgets, and OpenSocial ${ }^{\mathrm{TM}}$ profile applications.

Moderation \& Privacy - A network's creator may decide whether to make the network public for anyone to view, or private so that only members may view the content. There is also freedom to moderate photos, videos, groups, chat, and events before they are posted.

Latest Activity - A real-time activity feed of everything happening across your organization's social network. A network creator can choose the activities that are displayed.

Photos Feature - Members can be allowed to upload and share photos.

Branded Slideshows - Members can embed a social network's branded photo slideshow anywhere on the web and link back to a social network.

Video Feature - Members can be allowed to upload and share videos.

Branded Video Players - Members can embed a social network's branded video players anywhere on the web and link back to a social network.

Chat - Online members can chat in real-time with the persistent chat feature across the bottom of a social network or pop it out into its own window.

Discussion Forum - Each social network can include a rich single or multithreaded discussion forum with categories, photos, and attachments to a specific social network. Forum topics can be moderated. 


\section{Benefits}

- Can create any network imaginable

- Ability to designate some activities as admin-only

- Full content moderating capabilities

- Easy interaction with users

- Members are interested in specific topics

- Highly customizable to your organization's needs

- Customizing of features allows incorporation of your organization's unique branding and artwork into the social network

\section{Drawbacks}

- Difficult to sift through all the content

- Users can post negative reviews

- Any user is able to respond to any post

- All content is stored in the Ning database

- There is additional cost for a custom URL with just your organization name

- Niche topics can make it difficult to have a thriving community

\section{Monitoring}

Ning allows network creators to track new sign-ups with Google Analytics ${ }^{\mathrm{TM}}$. The statistics available include sign-up numbers, website visitors, length spent on the site, and more.

\section{How Can Transit Systems and Commuter Services Organizations Use Ning?}

- Create a network for consumers who use your organization's services

- Create a network of transportation organizations and professionals

$\sim$ Share ideas and content about how to increase efficiency within your respective organizations

\section{How to Set Up a Ning}

Ning has various features to choose from when creating your organization's social network. When beginning a profile, the first step involves selecting which features to utilize. For instance, would photo upload capabilities be useful? Blog discussion boards? Perhaps a calendar? A user has multiple features from which to choose. Your organization will also need to come up with a name for it's new social network along with a website URL. After this it's time to select the social network's appearance, which can be a pre-established template or one custom created.

For help getting started visit:

http://help.ning.com/cgi-bin/ning.cfg/php/enduser/std_adp.php?p_ sid $=7_{w} d X 97 F j \&$ _faqid $=3497$ 


\section{Example: My RVer}

This is a network targeted at people who travel via recreational vehicles. Members share their experiences on RV trips and also ask questions related to purchasing or traveling. http://myrver.ning.com/

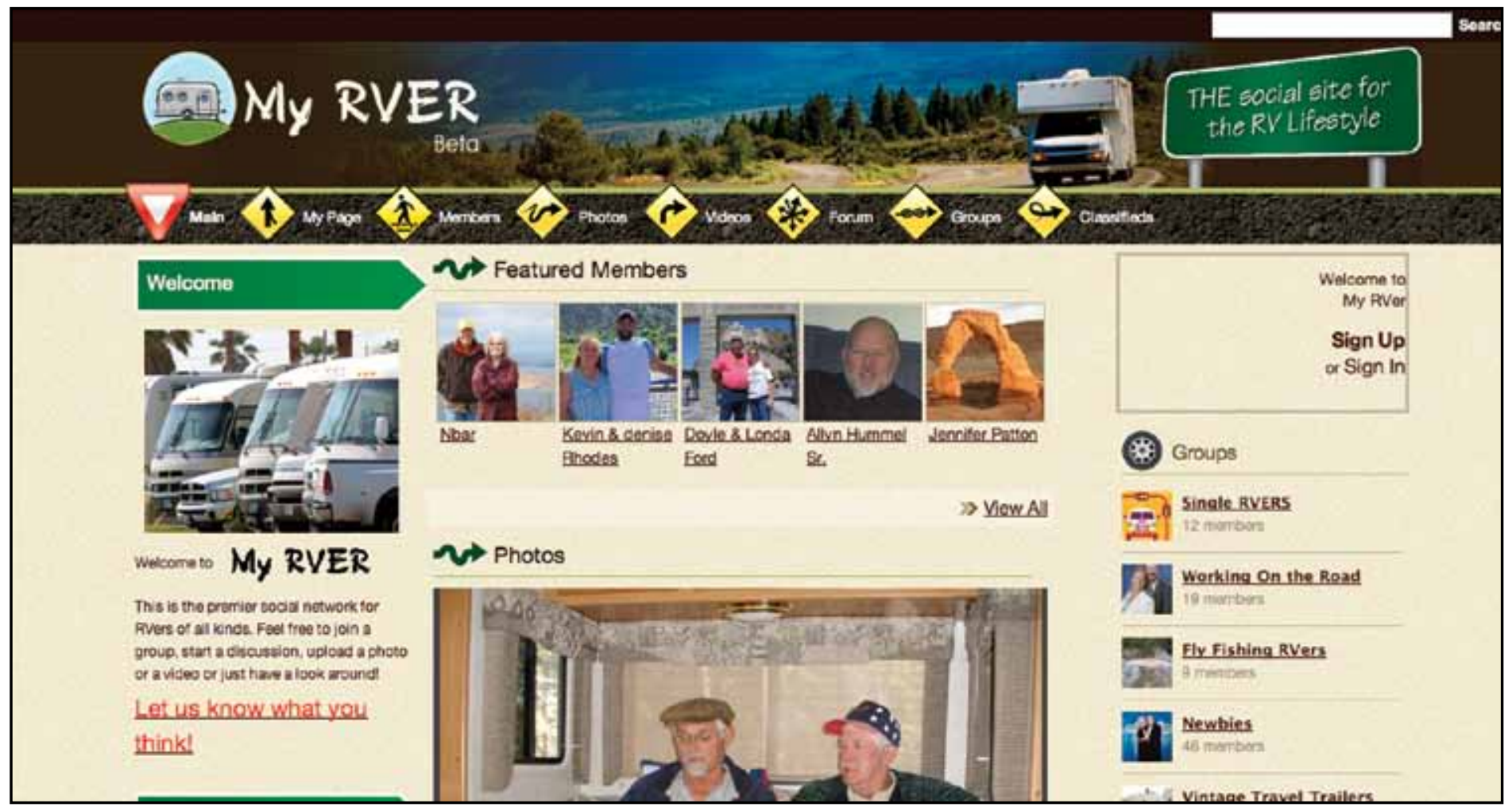

Figure 7: My RVer on Ning 


\section{Example: GovLoop}

This is a network targeting federal employees where members can discuss their jobs and help one another.

http://www.govloop.com/

Sgen Up Sign in Search Social Networh

\section{goveop}

\section{CONNEOTNG THE GOVERRMENT CONMUNTY}

Man My Page Members Bloge Groups Forum Jobs Events Multimedla Vdooe

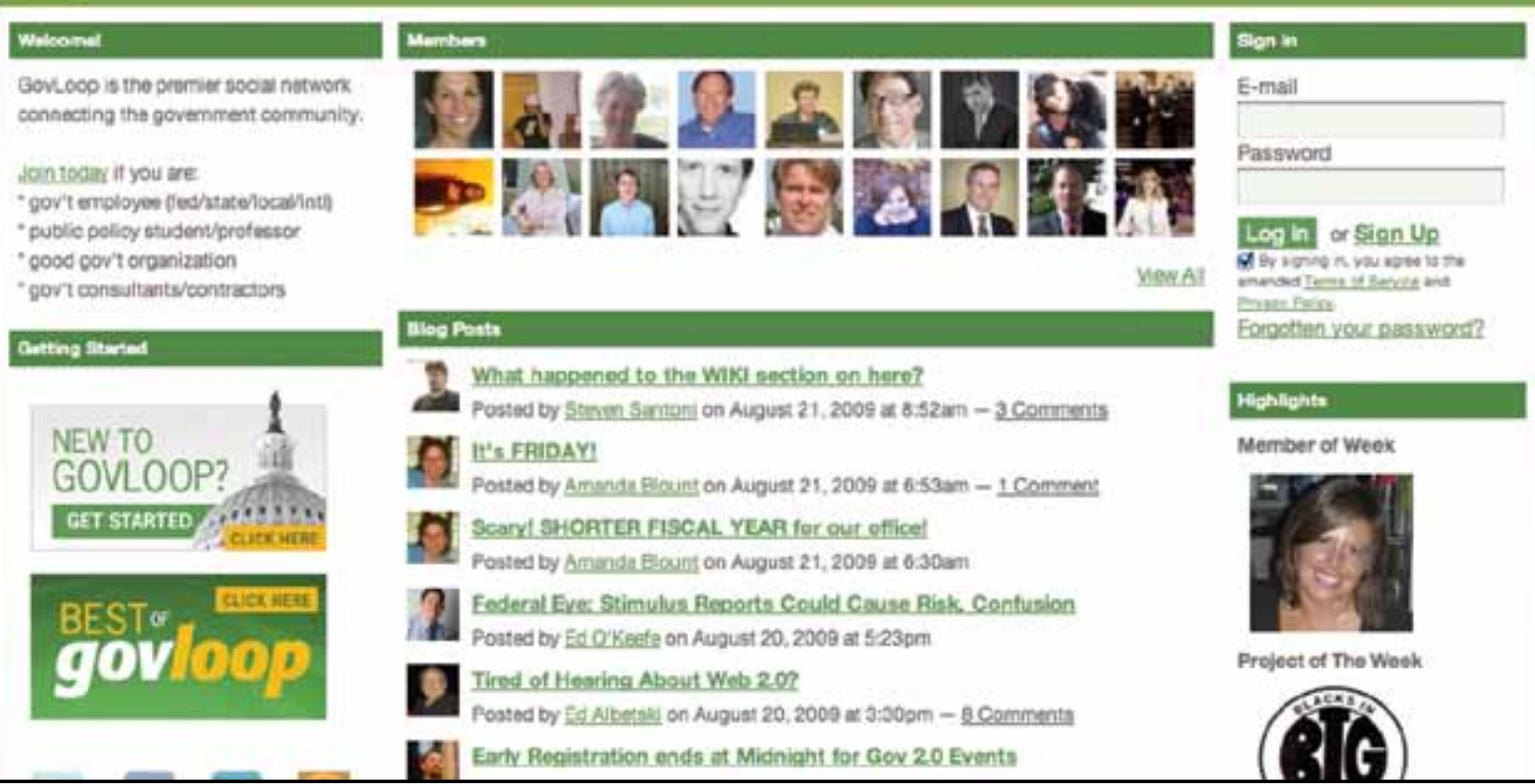

Figure 8: GovLoop on Ning 


\section{Example: Bioneers Room and Rideshare}

This network allows members traveling to the 2009 Bioneers conference to connect with each other to help coordinate rideshare efforts to and from the conference.

http://bioneers.ning.com/group/2009roomandrideshare/

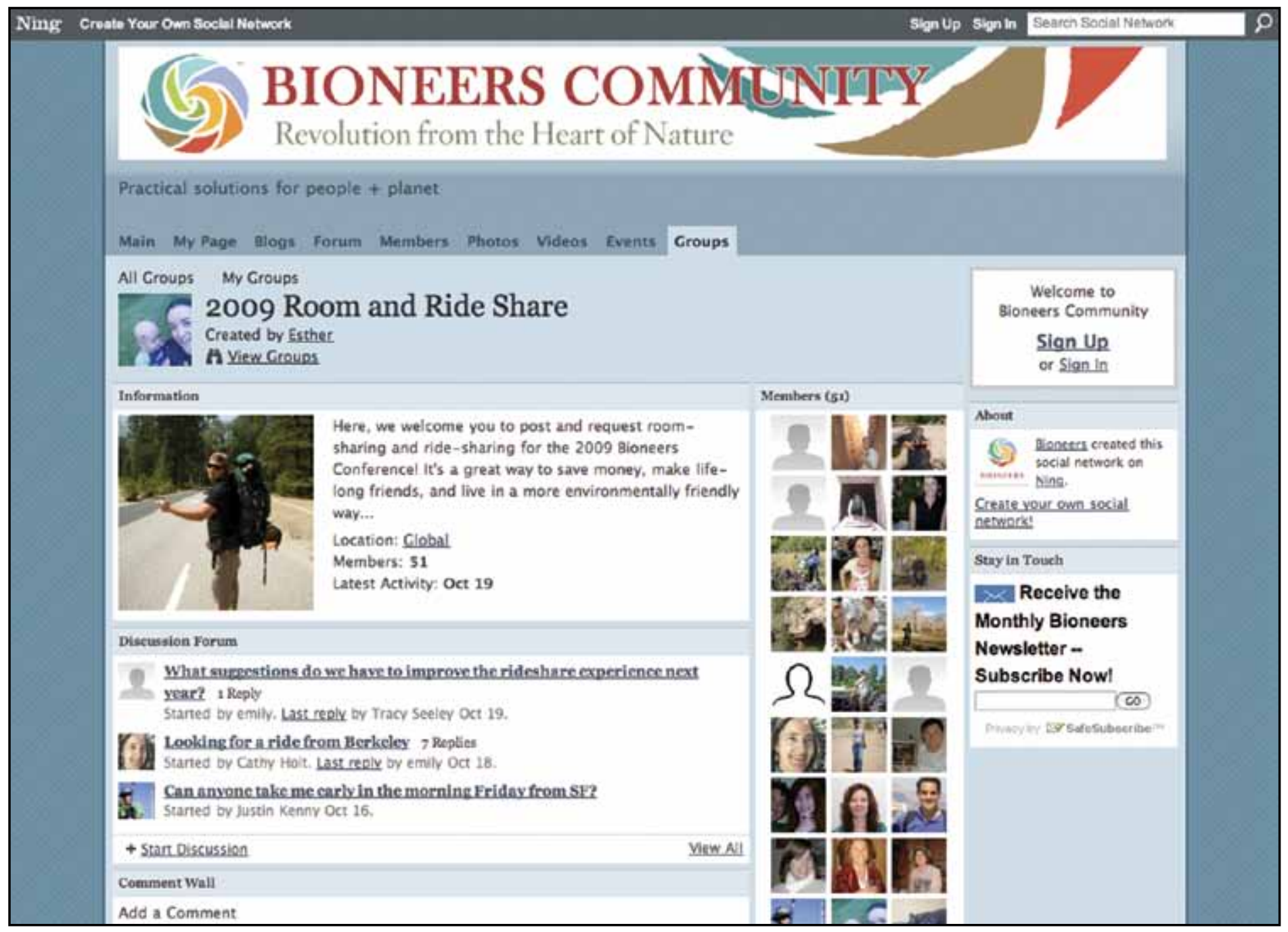

Figure 9: Bioneers Room and Ride-

share on Ning 


\section{LINKEDIN $^{\circledR}$}

\section{What is LinkedIn?}

LinkedIn is a network that helps to build professional relationships. Its purpose is to be connected to all your business contacts, and also have access to their contacts. Its 43 million members represent 170 industries and 200 countries. Creating an account is free, but members can opt to upgrade their accounts for either a monthly or yearly charge.

\section{Key Terms}

Profiles - Members fill in profiles with their education and career history. Members can control which portions of their profiles are private and public. Profiles can be found through LinkedIn search.

Groups - LinkedIn offers the option to create a group based on common interest, experience, affiliation, and goals. Users can search for groups by category using the Group Directory. Once in a group, members can participate in discussions and view the rest of the group members.

Answers - LinkedIn Answers ${ }^{\mathrm{TM}}$ allows users to ask a question and get feedback from other users, whether it is a question about knowledge, experience, or opinion.

Service Providers - LinkedIn provides a full directory of service providers.

News - LinkedIn provides an ample database of articles on a user's company, competition, and industry. A news module appears on each member's homepage, with news categorized by most read, company-related, competition-related, and industry-related.

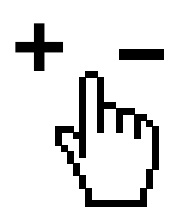

\section{Benefits}

- Organized network of connections

- Up to date information on a user's company, competition, and industry

- Ability to assert your organization as an expert

- Allows monitoring of conversations about your organization

- Good for business-to-business relations

- Ability to reach highly educated, young adults

\section{Drawbacks}

- Little communication with customers

- Network is smaller than most other social networking websites

- Purpose of LinkedIn is more specific to professional relationships 


\section{LinkedIn Search Capabilities:}

Different criteria can be used when searching through LinkedIn:

- By name or other distinguishing characteristics to find a specific person

- Advanced search targets specific skill-sets or areas

- Reference searches can be run on potential job candidates

- Inbox searches can retrieve important messages

- Find jobs and groups related to your organization's interests

\section{How Can Transit Systems and Commuter Services Organiza- tions Use LinkedIn?}

- Use as directory of connections

$\sim$ Users are meant to create a network that contains their real-life industry connections in order to collaborate on projects and facilitate making new connections.

- Position your organization as an expert by responding to users' questions 


\section{Example: Public Transit Professionals}

This group brings together transportation professionals and employers who are interested in sharing their knowledge, experiences, methodologies, business opportunities, new customer's indications, new solutions, papers, and other subjects pertaining to public transit.

http: / / www.linkedin.com/ groups?gid=1784344\&trk=anetsrch _name\&goback =.gdr_1249070001152_1

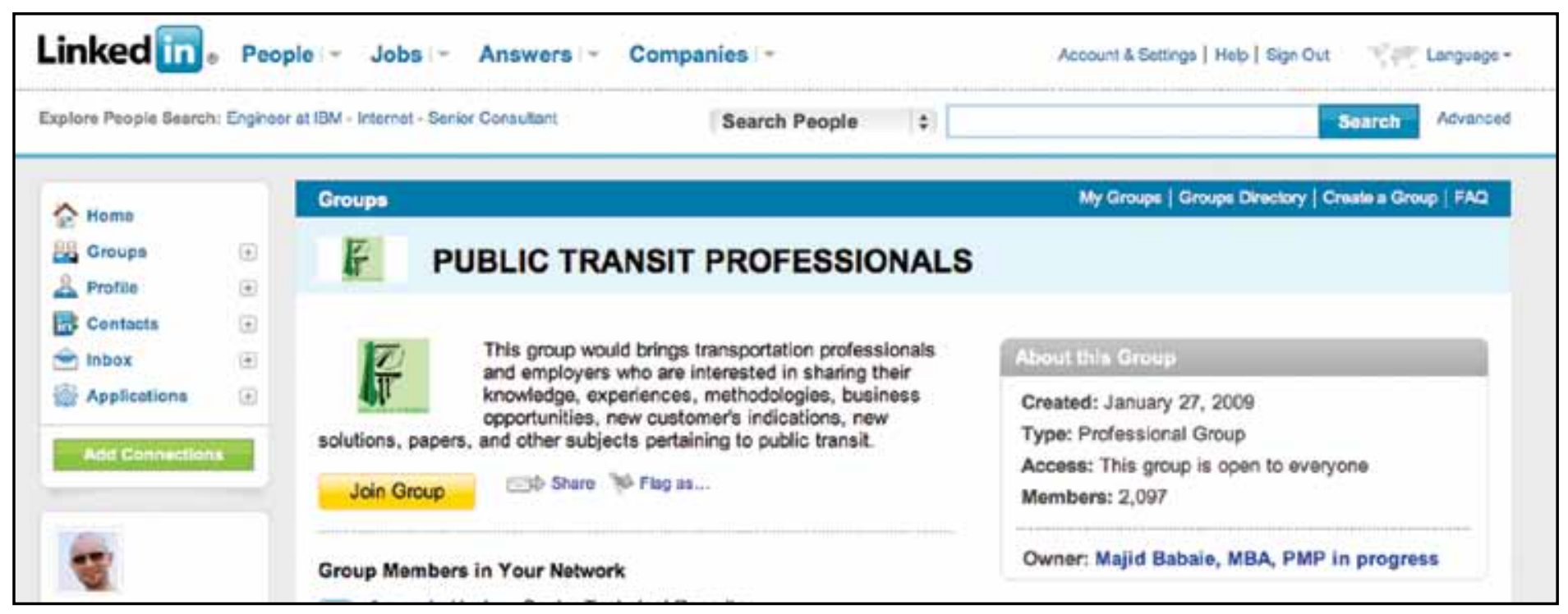

Figure 10: Public Transit

Professionals on LinkedIn

\section{Example: Carpool}

This group helps users coordinate carpools among geographic areas as well as carpools within their specific company.

http:/ / www.linkedin.com/groups? gid =1950377

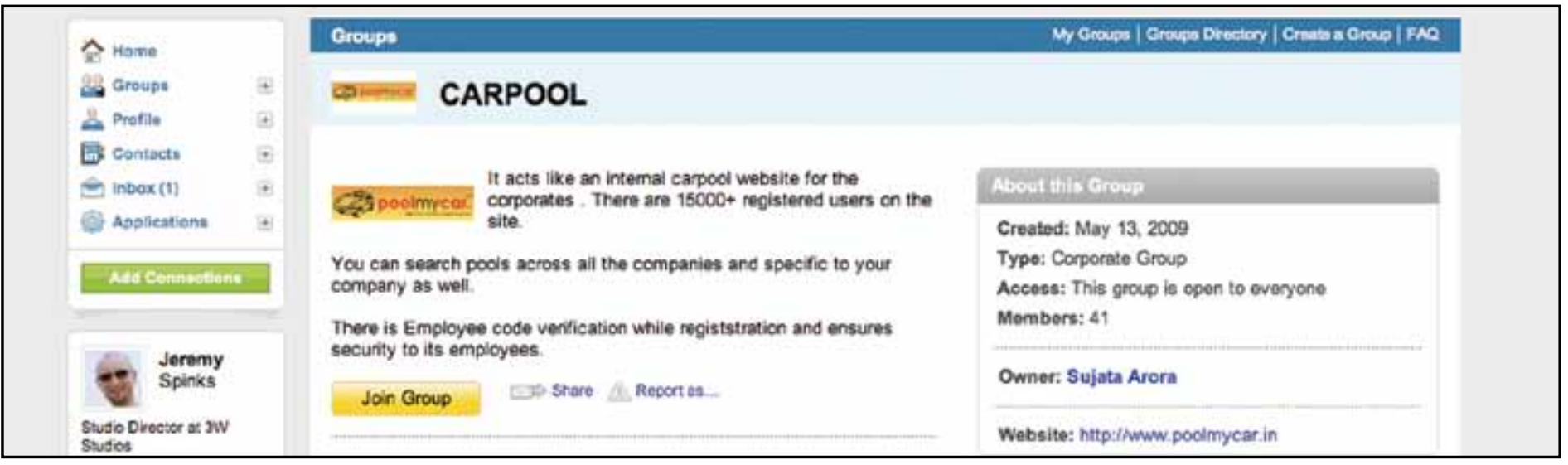

Figure 11: Carpool on LinkedIn 


\section{How to Set Up a LinkedIn Account}

To set up an account, it will be helpful to have organization history and details available, as this type of data is critical during account setup. For help getting started visit: http://learn.linkedin.com/new-users/

\section{SECOND LIFE ${ }^{\circledR}$}

\section{What is a Second Life?}

Second Life is a virtual world that allows users, called Residents, to interact, explore, socialize, participate in individual and group activities, travel the virtual world, or create and trade virtual property and services. To participate, users must be over 18 years old. Users 13 to 17 years old may participate in Teen Second Life.

\section{Key Terms}

Avatar - a computer user's representation of themselves through a threedimensional model. It is the physical representation of the user.

Grid - this refers to the world in Second Life as a whole.

Residents - this refers to users who play Second Life.

Linden Dollar (L\$) - Second Life's internal currency that can be used to buy virtual items, goods, or services.

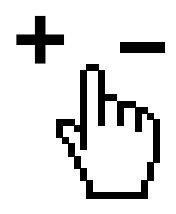

\section{Benefits}

- Easily accessible

- No charge to begin playing

- Has a strong following of loyal fans

- Users are passionate and highly involved

\section{Drawbacks}

- Requires constant upkeep

- May be difficult to start

- Reaching target audience is difficult because the user's virtual identity is vastly different from the user's real world identity

- Lack of Monitoring 


\section{Monitoring}

Due to the nature of Second Life, there is currently no way to monitor for keywords or mentions.

\section{How Can Transit Systems and Commuter Services Organiza- tions Use Second Life?}

- Promote your organization's services on Second Life by creating a virtual transit system

- Create awareness of your organization by advertising in the virtual realm

\section{Examples}

Bay Area Rapid Transit partners with a Second Life convention to advertise transportation services.

http: / / www.slconvention.org/logistics / parking-and-transportation-for-all /

Ontario Public Services uses Second Life as a testing site for real life situations and to recruit employees.

http: / / www.itbusiness.ca/it/client/en / home/News.asp?id=50198

\section{How to Set Up a Second Life Account}

To begin exploring Second Life, an account filling out personal information such as your first name, last name, and birthday must first be created. Then you must download the software to play in Second Life. For more help setting up an account visit:

https: / / support.secondlife.com/ics/support/default.asp?deptID=4417\&task $=$ knowledge\&folderID $=208$ 


\section{Written Blogs}

\section{WHAT IS A BLOG?}

In this chapter

Livejournal

Blogger

WordPress

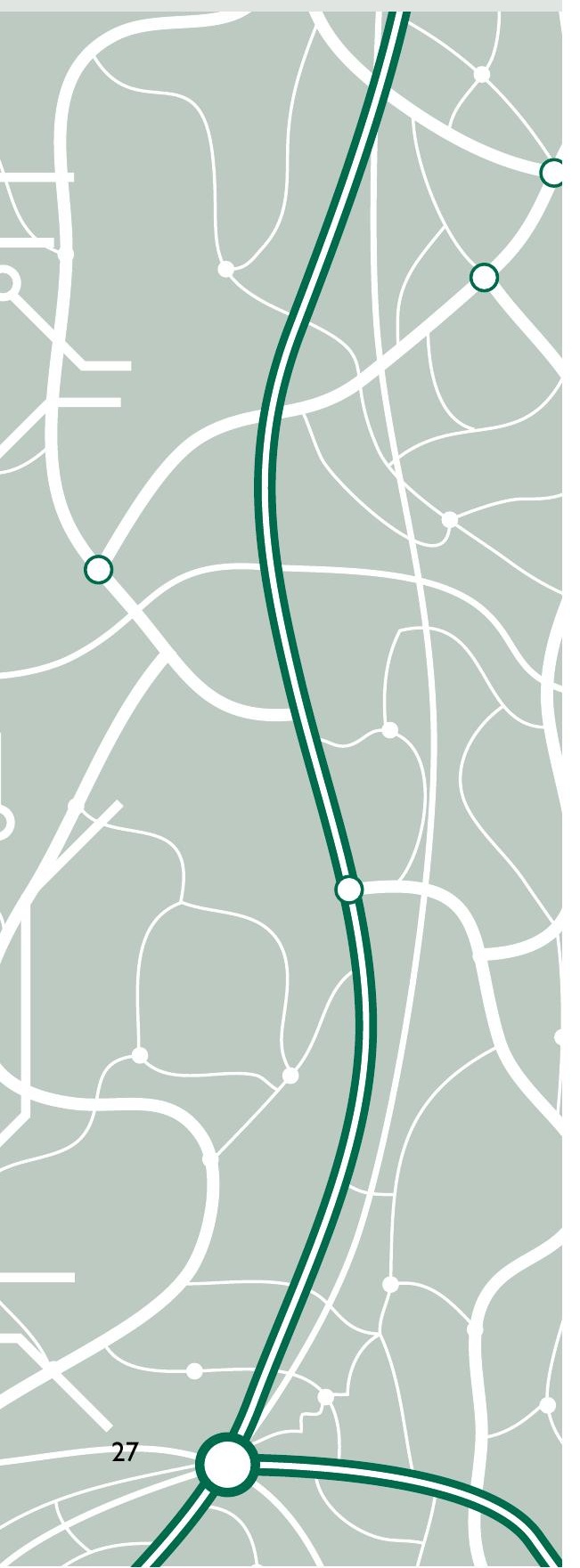

Blog - short for Weblog - is an online site where authors craft entries or articles. Topics can range from news, personal stories, industry trends, product information, and everything in between. Generally speaking, there are three types: personal blogs, genre-specific blogs, and corporate blogs.

Personal blogs serve as an online journal where users document their lives. These blogs can contain important information about your organization through the eyes of the consumer.

Genre-specific blogs focus on a particular issue. These bloggers are seen as experts in their particular field and are often key influencers. It's helpful to have a connection with the major blogs in your organization's particular field.

Corporate blogs are run by corporations. Corporate blogs serve as a forum where companies can discuss their products or services, react to public opinion, or clarify policies. These can be a great way to start your organization's foray into social media and can also be an excellent source for monitoring competition.

Blog posts should include at least one form of multimedia. While your organization's blog post may be well-written and insightful, it's just a block of text until someone starts reading it. Pictures and videos break up the text and serve as bait to get readers interested in what your organization has to say.

Visitors can subscribe to blogs, and communicate with the author through comments. It's important to acknowledge comments from time to time, but it's not necessary to respond to each comment. Blogs should be updated frequently, and reflect the personality of the author.

Some print publications are using blogs to create web-based versions of their established print publications, like newspapers and magazines, where readers can comment and rate articles. 


\section{Key Terms}

Blogging - Refers to authoring, maintaining, or adding an article to a blog.

Blog Post / Post / Entry - Individual articles on a blog.

Blogger - the blog author or those who are authorized to post content to a blog.

Tags - keywords that describe the blog entry or are covered in the blog entry as specified by the blog author. By adding tags to blog posts, readers are able to search through these tags to read blogs on specific subjects.

Permalink - The unique URL of a single post. This is the URL to use when directing readers to a single blog post.

RSS feed - Readers can use an RSS feed reader to "subscribe" to specific blogs. With each now blog post the RSS reader will then update automatically.

Trackback - Trackbacks allow bloggers to reference other blogs that inspired their blog post. Trackbacks display the inspiration blog below the blog post. This is a great way to network and build a community on specific topics. Think of a trackback as a tap on the shoulder of a fellow blogger.

\section{Why create a blog?}

While social networks allow your organization to engage with its audience, establishing a blog is a way to disseminate information centered more on your organization. Detailed descriptions about new services or explanation of changes within your organization can be posted. It's a more professional and elaborate means of communicating serious topics in comparison to a note on Facebook or a post on Twitter. Your organization may also be in a position where blogging would be beneficial in responding to customer complaints. Additionally, this tool can be used to help address frequent concerns and then direct further inquiries into that subject by sending a link of that post to your organization's consumers. 


\section{Benefits}

- Can craft blog entries on very specific niche topics

- Readers are often highly dedicated

- Entries are free to read and access

- Archived news is readily available and free to access

\section{Drawbacks}

- Online publications are not subject to journalistic standards

- Material is published often and recent news becomes old fast

- Must set boundaries for your organization's employees as to what practices are appropriate for their personal blogs

\section{Monitoring}

There are several ways to monitor blog conversations. The following is an overview:

Google Analytics ${ }^{\mathrm{TM}}$ is a free tool which offers bloggers the ability to track what is popular on their blog, what brings visitors into their blog, where their visitors are located and whether they visited directly or were referred by a search engine.

Technorati ${ }^{\mathrm{TM}}$ is a blog search engine, which organizes blogs based on their tags and indexes them by popularity. When your organization registers with Technorati, then you can check your ranking weekly to gauge yourself against other blogs in your field.

Google Alerts ${ }^{\mathrm{TM}}$ allows users to be alerted by email whenever their username, company name, website URL or any other keywords of their choosing are mentioned on the Internet. This can be used to track mentions of your organization's blog or company.

Feedburner ${ }^{\mathrm{TM}}$ is an RSS tool that allows users to register their blog and gather information on who is subscribing to their blog. Feedburner also allows your organization the option of allowing readers to receive blog updates via email.

RSS Feeds: If your organization signs up for an RSS feed reader, like reader.google.com, you can "subscribe" to new updates from online publications - such as a transit magazine. 


\section{The Dos and Don'ts of Blogging}

Do

- Encourage your organization's bloggers to write in first person

- Feature a blog link on your organization's home page

- Include hyperlinks in your organization's blog post

- Include interesting multimedia, like pictures and video

- Reference other bloggers and their posts

- Comment on other blogs

- Respond to comments in your organization's blog and reference them

- Spend some time every day reading other blogs

- Share knowledge about your organization's area of expertise

- Include new writers to keep content fresh

- Include your organization's readers by asking their opinion

- Set boundaries for your organization's employees in terms of writing on the company blog or their personal blogs. If an employee has a personal blog, it's a good idea to have explicitly state that their views do not reflect the views of their employer.

Don't

- Ignore comments visitors make

- Plagiarize other blogs' content

- Spam other blogs just to get your organization's name out there

- Constantly attempt to sell your organization's services, but it's okay to reference them

- Require visitors to login to view your organization's blog or to leave a comment

- Badmouth your organization's competition

- Abandon your organization's blog, it takes time and work to create a community

\section{How Can Transit Systems and Commuter Services Organiza- tions Use Written Blogs?}

- Increase awareness of your organization

$\sim$ Share company news, event photos, etc.

$\sim$ Comment on industry trends

- Position your organization as an expert

$\sim$ Become the source for industry news 


\section{Example: Seattle Transit Blog}

This system utilizes the online blog to keep the community updated on local transit happenings. They are able to tag entries and categorize them appropriately.

http:/ /seattletransitblog.com/

\section{Seattle Transit Blog}

Auguat 6, 2005 at 3235 am

The Council Metro Plan

by Martin H. Duke

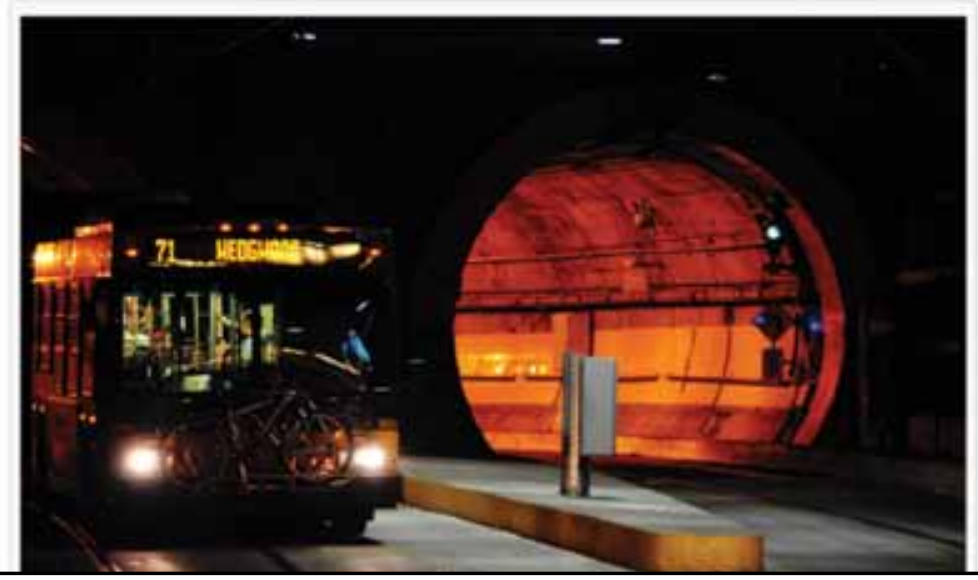

FEEDS

D Elog Entries (RSS)

Q Comments (RSS)

1] Twitter

CONTACT US

seattletranaitblog6rmail.cum

RECENT POSTS

The Council Metro Plan

Followup On Sounder To Lakewicod

Reminder: Meet-up

Tomorrow Sight

Sore Pay Parking

Seattle City Counci!

Endorsements

Editorialı You've Had Quite Long Enough, Get tt Done

Nevrs Round-Up

Figure 12: Seattle Transit Blog

\section{Additional Written Blog Examples:}

The New York Times Wheels Blog is dedicated to all things automotive. This blog has a readership of approximately 68,267 monthly people.

http://wheels.blogs.nytimes.com /

Transport Topics Online outlines trucking and freight transportation news.

http://www.ttnews.com/

Reinventing Transit is the official blog from the Environmental Defense Fund. This blog features news and updates about transit organizations becoming eco-friendly.

http: / /blogs.edf.org/transit/

Transportation for America Blog is the official blog for the Transportation for America organization campaign.

http://t4america.org/blog/ 
Get Downtown Blog is focused on commuting opportunities in Ann Arbor including, ridesharing, bicycling, carpooling, walking and the use of available public transportation.

http: / / blog.getdowntown.org/

\section{Blogging Services}

The three most common free blogging services are LiveJournal, Blogger and Wordpress. An analysis of each will follow.

\section{LIVEJOURNAL ${ }^{\circledR}$}

\section{What is Live Journal?}

LiveJournal is an online journal service with an emphasis on user interaction. Most LiveJournal users create genre-specific or personal blogs. A basic, fully-functional account is free, while Paid accounts receive access to premium features.

\section{Key Terms}

Friends - LiveJournal's Friends system is part of the community element of the site. A user's Friends list is used to show entries on the user's Friends page and restrict access to entries and other site features.

Mutual Friends - These are users that have added your organization as a friend and your organization has added as a friend.

Custom Friends Groups - This is a way to organize your organization's Friends list into customized groups.

Community - A community is basically a journal run by a member of LiveJournal for people with common interests that allows for multiple members to post.

Memories - These allow users to organize their favorite LiveJournal entries with a keyword archive system. This does not affect the original entry posted in a user's original journal, a community, or another person's journal. Like journal entries, memories can be marked with different security levels.

Calendar/Archive - The Calendar view, also known as the Archive view, serves as a record of previous entries. As users post entries into their journal, each one is archived on the user's Calendar by posting date, so that it can be located later. 


\section{Benefits}

- Individual blog entries can be set as public or friends-only depending on the content

- Can filter content based on friend groups

- Customization allows programmers or web designers in your organization to stay in line with your visual identity like color schemes and logos

- RSS feed available

\section{Drawbacks}

- LiveJournal's terms of service prohibit the use of a journal to purely advertise products and services

- It takes a time to build up a friends list

- Extensive moderation is critical and time consuming

\section{Monitoring}

There are two formats LiveJournal has created for monitoring blog conversation.

LjSeek.com: a 3rd party website that allows your organization to search for LiveJournal groups, journals, posts, tags, images, and forums for key words. These can be subscribed to as an RSS feed for a search of certain terms - similar to a Google alert.

LiveJournal Search: allows for searching by region, community or other criteria, but most of these advanced search features are only available to Paid or Plus account members.

\section{How Can Transit Systems and Commuter Services Organiza- tions Use LiveJournal?}

- Use LiveJournal to connect to other organizations in the industry

- Create a community around your organization

$\sim$ Example: Ottawa/Ontario Transportation Group

http: / / community.livejournal.com/octranspo

$\sim$ Example: Unofficial community for TriMet in Portland, Oregon

http://community.livejournal.com/trimet/

- Use LiveJournal to host a company blog

$\sim$ Example: Arizona Department of Transportation

http://azdot.livejournal.com/

\section{How to Start a LiveJournal}

To create a LiveJournal your organization will need a valid email address and creation of a username. Next your organization can customize your LiveJournal's appearance and create groups. For help getting started visit:

http://www.livejournal.com/support/faqbrowse.bml?faqid=104 


\section{BLOGGER $^{\mathrm{TM}}$}

\section{What is Blogger?}

Blogger is Google's free blogging tool. It can be accessed at Blogger. com.

\section{Key Terms}

Blogfeed - The XML-based file into which blog hosting software embeds a machine-readable version of a blog to allow it to be syndicated for distribution, often through RSS and Atom.

Blog Admin - An administrator of a team blog has access to the blog's settings and template, as well as the ability to edit and delete posts made by other members of the blog. Additionally, they can add or remove other team members. More than one member can have admin rights to a single blog.

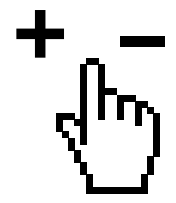

\section{Benefits}

- Customization allows for your organization to create a blog with content, backgrounds, polls, and templates in line with your organization's visual identity

- Comments can be approved or deleted

- Blogger is owned by Google and is indexed highly on their blog search engine

- Blogger allows your organization to set up custom domains and move your existing blog

- Easy to use

\section{Drawbacks}

- Full Disclosure

- Customization is limited for users who want to alter layout and format

- Your organization must make users aware of the blog

- Requires keeping up with the blog on a regular basis to keep people reading 


\section{Monitoring}

Feedburner is an RSS tool that allows users to register their blog and gather information on who is subscribing to their blog. Feedburner also gives an organization the option of allowing readers to receive blog post updates via email.

\section{How Can Transit Systems and Commuter Services Organiza- tions Use Blogger?}

- Create a branded blog to spread information regarding your organization

$\sim$ Example: Transportation Security Administration

An official blog about news, updates, and tips when traveling in the U.S. - http://www.tsa.gov/blog/

\section{How to Start a Blog Using Blogger}

To create a Blogger account your organization must either use an existing Google Account or create one. Blogger allows users to fill out a profile and customize their background content. For help getting started visit:

http: / / www.blogger.com/features\#gettingStarted. 


\section{WORDPRESS $^{\circledR}$}

\section{What is WordPress?}

Wordpress is a free blogging service and is a favorite among writers and creators of corporate blogs.

\section{Key Terms}

Pages - Feature which allows users to easily create web pages. For example, your organization could add an about us page with a company biography, and a link to that page would be automatically added to the sidebar.

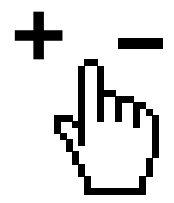

\section{Benefits}

- Seen as a more professional blogging services

- Allows for higher customization

\section{Drawbacks}

-Wordpress customization can be difficult and time-consuming

\section{Monitoring}

Stats System: This feature is designed to give users up-to-the-minute stats on: number of people visiting the blog, where they're coming from, which posts are most popular and which search engine terms are sending people to your organization's blog.

\section{How Can Transit Systems and Commuter Services Organiza- tions Use WordPress?}

- Create a branded blog to spread information regarding your organization

$\sim$ Example:Tri-State Transportation Campaign

Official blog about news and updates on the campaign and transportation in the region.

$$
\text { http: / /blog.tstc.org/ }
$$

\section{How to Start a Blog on WordPress}

To sign up with WordPress users must create a blog domain name, which will serve as the blog URL, and a Blog title, which can be changed at any time. After that the profile can be filled out, which is optional, and the appearance of your organization's blog can be customized. For more information visit:

http: / / support.wordpress.com/getting-started / 



\section{iTUNES ${ }^{\mathrm{TM}}$}

\section{What is iTunes?}

iTunes is a free application developed by Apple, Inc. for computers running both Macintosh and Windows operating systems. It plays digital music and video, syncs content to an $\mathrm{iPod}^{\mathrm{TM}}$ or iPhone ${ }^{\mathrm{TM}}$, and includes an online store filled with various content. It can be accessed offline to organize, watch, and listen to your content.

\section{Key Terms}

Subscribe - iTunes will automatically deliver new episodes to a user's iTunes ${ }^{\circledR}$ podcast playlist.

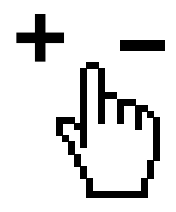

\section{Benefits}

- iTunes is a well-known and highly used service

- Free to upload podcasts on iTunes

- Search makes it easy for users to find your organization's content

- Automatic updating allows for ease of syndication

\section{Drawbacks}

- A basic knowledge of production is needed to create quality podcasts

- iTunes does not host any podcasts on its server

- If content receives low ratings it can deter future users from accessing it

\section{Monitoring}

All monitoring must be done from the source where the podcast is hosted (ie: using log analysis on the host server, such as Google Analytics). iTunes itself does not monitor the podcast views or subscribers.

\section{How to Create and Upload a Podcast}

To upload a Podcast to iTunes your organization must have a valid iTunes ID. Podcast producers must submit their Podcast via the iTunes store and wait for approval by Apple. For more information visit: http: / / www.ehow.com/how_4479769_upload-podcast-itunes.html 


\section{PODCAST.COM}

\section{What is Podcast.com?}

Podcast.com allows users to search for, watch, listen to, download, subscribe to, and share podcasts. One can also manage a collection by adding, organizing, and deleting podcasts. Podcast.com also allows users to find other members and see what Podcast they are subscribing to.

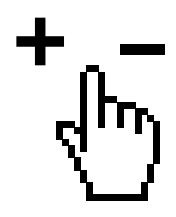

\section{Benefits}

- Seeking out members with similar likes makes it easy for users to find and share content

\section{Drawbacks}

- Not as widely-used as iTunes

- A basic knowledge of production is needed to create quality podcasts

- Podcast.com does not host podcasts

- If content receives low ratings it can deter future users from accessing it

\section{Monitoring}

All monitoring must be done from the source where your organization hosts the podcast (ie: using log analysis on the host server, such as Google Analytics). Podcast.com itself does not monitor the podcast views or subscribers.

\section{How Can Transit Systems and Commuter Services Organiza- tions Use iTunes or Podcast.com?}

- Create awareness through creation of a regular transportation series (audio or video)

$\sim$ Update the community on system milestones

$\sim$ Report on industry trends

- Use a podcast as an aid for riders with visual impairments, hearing impairments, or developmental disabilities

$\sim$ Start a podcast (audio and video) for riders who may need extra instruction on how to use your organization's services, such as tips on locating exits or entering and exiting vehicles

- Start a podcast to recap meeting minutes from board meetings or city council meetings

\section{How to Create and Upload a Podcast}

To add a Podcast you must first have it hosted on another site. To submit a Podcast to Podcast.com on the homepage click "Add a Podcast" and insert your organization's Podcast RSS feed. For more information visit http://blog.podcast.com/podcastcom-faq/ 


\section{Example: Connections}

The Chicago Transit Authority posts monthly 30 minute television programs. The following site houses all their video posts. Shows can be categorized to facilitate easy searching by end users.

http://podcast.com/show/25946/Connections /

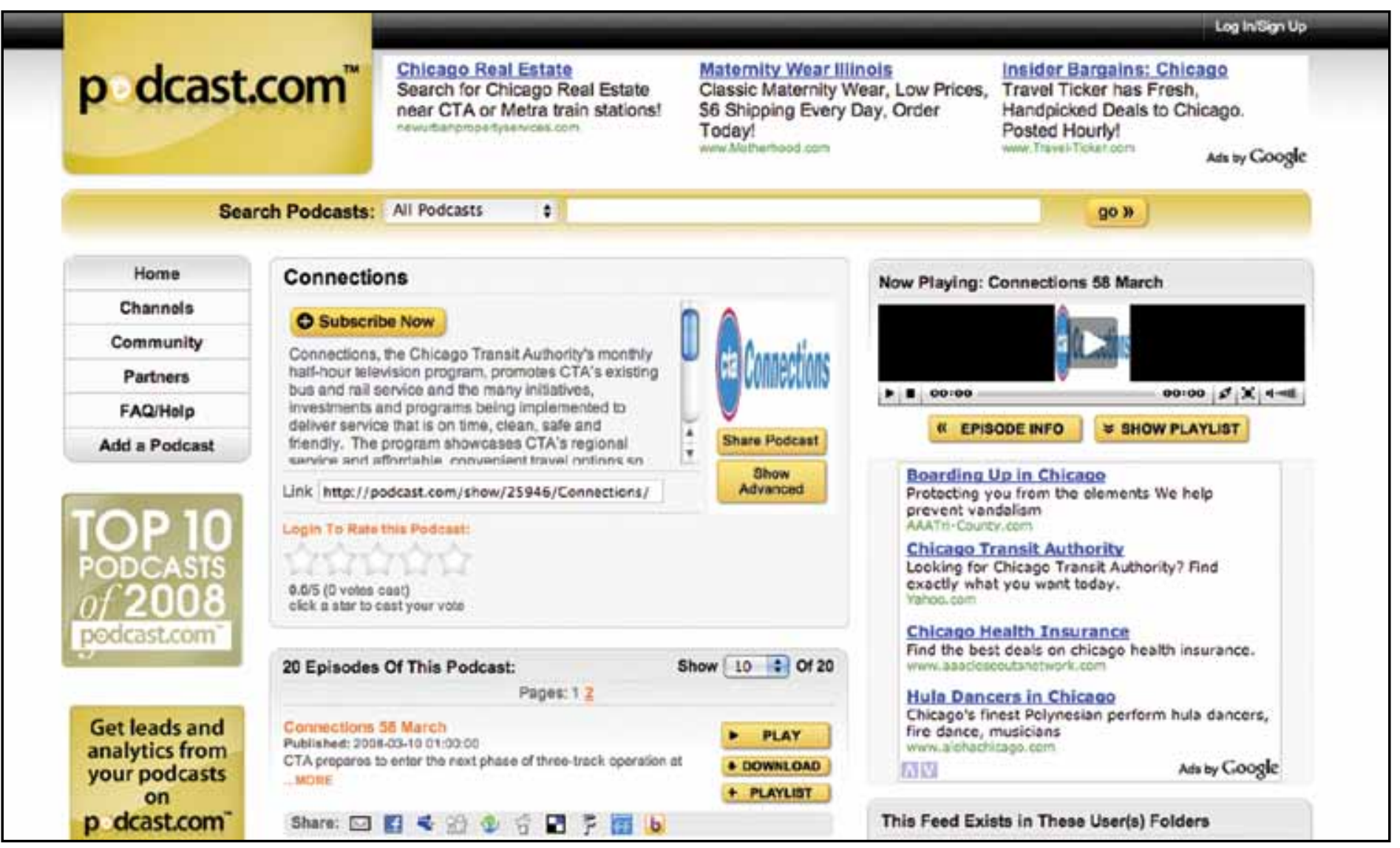

Figure 13: Connections on

Podcast.com 


\section{Microblogs}

In this chapter

Twitter

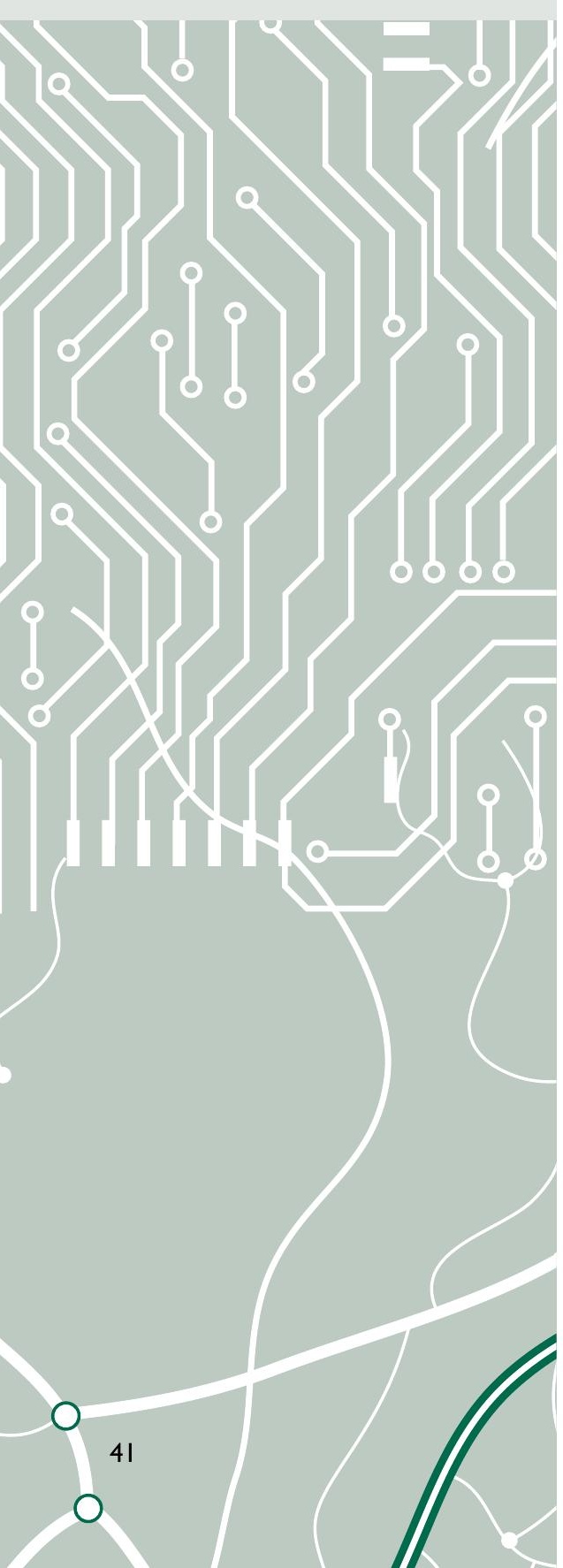

\section{WHAT IS A MICROBLOG?}

Microblogs are a condensed version of the written blog. They require short posts that are limited by a character limit. They often contain quick thoughts, links to a full length blog post, or links to multimedia (video or pictures). The most common microblogging platform is Twitter.

\section{Twitter $^{\mathrm{TM}}$}

\section{What is Twitter?}

Twitter is a web-based micro-blogging service, which allows users to send messages called tweets that are 140 characters or less to all of their followers. Tweets can vary in substance, from random thoughts of the sender, to current news or events commentary. Followers can be anyone from anywhere, and the primary goal of the Twitter system is to network with as many followers as possible.

In turn, users are encouraged to follow other users. Usually this is comprised of:

- People the user knows

- Those who interest the user

- Those who are in the same business or networking arena as the user

It is very common for people to reciprocate those who follow them, hence growing everyone's network. Additionally, this tool has some advantageous search capabilities. Twitter allows users to find assorted tweets by user in a particular city/region/state - allowing your organization to tap directly into a target audience.

Twitter is available to users via:

- Home page at www.Twitter.com

- Third party computer applications (Such as Seesmic or TweetDeck)

- Smartphone applications

- Text messaging 


\section{Key Terms}

Tweet - A message sent on Twitter. Tweets can be no longer than 140 characters.

Follow - Following a user means that your organization voluntarily and automatically receives their tweets on your home feed.

Retweet - A retweet (RT) is a re-post of another user's message. The format of these messages is as follows: RT @OriginalUser Original Message. It allows your organization to broadcast another's message to your network.

Tweet $U_{p}$ - A Tweet Up is a gathering of Twitter users organized online.

Hashtags - Hashtags are words prefixed with a hash (\#) symbol. These tags allow for conversations to be grouped by key words, clicking on a hashtag will take a user to a Twitter search of all occurrences of that specific word.

Bot - Bots are automated systems that automatically operate on Twitter. There are bots for activities such as: follow approval, follower finder, and posting links to blog posts. Though Bots can be useful it is important to use them wisely. Social media is all about conversation and people can't talk to a robot.

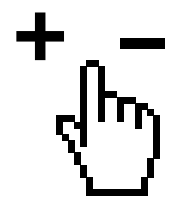

\section{Benefits}

- Facilitates 2-way conversation with customers

- Can search users by geography (place name, zip code or GPS coordinates)

- Audience seeks out your organization's message

- Easily accessible

- Easily monitored via keywords

- No costs to setup account

- Real times updates

\section{Drawbacks}

- Customers can express discontent

- Potential for negative customer relations with real-time feed 


\section{Monitoring}

Twitter offers your organization the unique opportunity to monitor its business or industry in real-time and then respond to customers instantly. For businesses there are a host of options when it comes to the issue of monitoring many of them are free.

Twitter Search is the only official monitoring tool offered by Twitter. Twitter search allows users to search all public tweets that have been sent within 1.5 weeks or up to 1,500 search results. Twitter Search also gives the user the ability to pinpoint the search based on a geographic area. Your organization can use this tool to search any combinations of keywords.

Tweet Beeps is a service that allows a user to input a specific word or phrase and be alerted whenever there is a tweet about that word or phrase or a business's website. Alerts are sent out every 30 minutes. Tweet Beeps is a free service with an option to upgrade to premium for $\$ 20$ a month with the added ability of 15 minute updates.

Tweet Grid allows users to create a real-time grid of Twitter searches which auto update as tweets come in. Users can create a grid of up to nine unique Twitter searches.

Desktop applications: Third party applications offer a more convenient Twitter experience. They roll a combination of features to make it easier to share media as well as communicate with followers. All major third-party desktop applications include the ability to run live real-time searches.

\section{How Can Transit Systems and Commuter Services Organiza- tions Use Twitter?}

- Customer Relations

This is one of the most useful ways to use Twitter, but it is the most time consuming. In this example, constant searches running your company name, industry, and keywords/phrases using www.search. twitter.com are conducted. It is critical that your organization doesn't just watch, but respond to users talking about your transit system or industry. These accounts have a large amount of customer contact and help to foster relationships with your target audience.

- Information Center

These accounts are extremely useful in establishing your organization as an expert in a field, and fall between the extremes of Bots and CRM (Customer Relations Management) in terms of user interaction. These accounts send out links and information about their specific industry. 


\section{Example: San Francisco Bay Area Rapid Transit}

http: / / twitter.com/sfbart

\begin{tabular}{|c|c|}
\hline $\begin{array}{l}\text { Through the exchange of quick, frequent answers to one } \\
\text { simple questicon: What are you doing? Join today to start } \\
\text { recelvins SFaART's tweets. }\end{array}$ & Amituntare \\
\hline b̈ö SFBART & 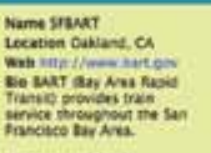 \\
\hline SF Ferry Bldg will do quake drill & $997,5,092$ \\
\hline $\begin{array}{l}\text { tomorrow from 8-8:45 a.m.... } \\
\text { Blue Bottle \& Peet's requlars take }\end{array}$ & Teress \\
\hline note! Details: & nowern \\
\hline http://twurl.nl/ehfsof & 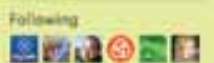 \\
\hline 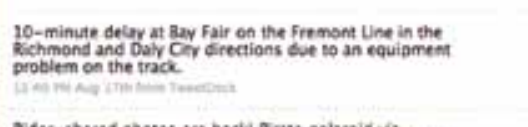 & 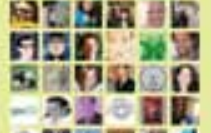 \\
\hline 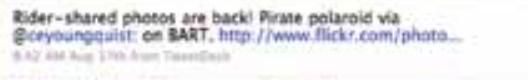 & 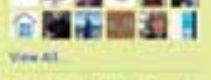 \\
\hline 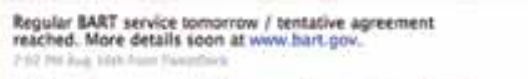 & 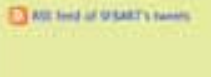 \\
\hline 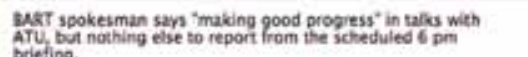 & \\
\hline
\end{tabular}

Figure 14: SFBART on Twitter

\section{Example: Friends of Transit}

http://twitter.com/rapidyes

\begin{tabular}{|c|c|}
\hline $\begin{array}{l}\text { New Blog Post: The Thank You } \\
\text { Edition http://u.mavrev.com } / 3 \mathrm{czr}\end{array}$ & 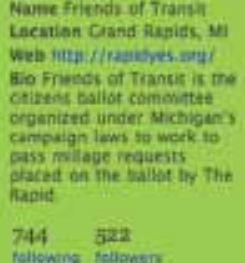 \\
\hline 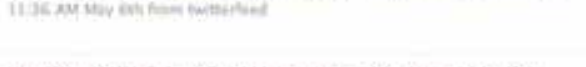 & Tweets ags \\
\hline $\begin{array}{l}\text { Thanks to all of the Silver Line supporters. We appreclate } \\
\text { your efforts with volunteering, taiking to the community and } \\
\text { voting YES. }\end{array}$ & Faventes: \\
\hline 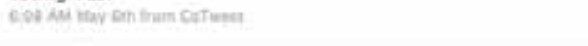 & follutiog \\
\hline $\begin{array}{l}\text { Fifteen more minutes for you to help make history by voting } \\
\text { YES for the Sllver Line and bringing the first BRT system to } \\
\text { West Michigan. } \\
\text { if }\end{array}$ & 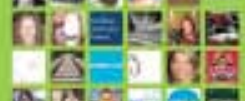 \\
\hline 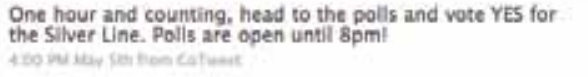 & $\because$ a \\
\hline You have 2 hours left untli the polls close. Make your YeS & $\sin \sin _{2}$ \\
\hline 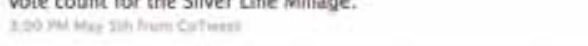 & 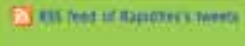 \\
\hline 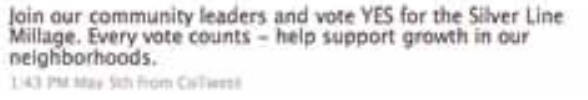 & \\
\hline $\begin{array}{l}\text { Millage day today. Help make history and vote YES for West } \\
\text { Michigan's first BRT systeml }\end{array}$ & \\
\hline
\end{tabular}

Figure 15: Friends of Transit on Twitter
Michigan's first BRT system 


\section{How to Set Up a Twitter Account}

To set up a Twitter account, your organization will need to create a profile with your organization's name, location, website and a short bio. For help getting started on Twitter, visit:

http://help.twitter.com/portal

\section{Example: Rideshare USA}

Streams ride share opportunities for 66+ US cities.

http://twitter.com/Rideshare_USA

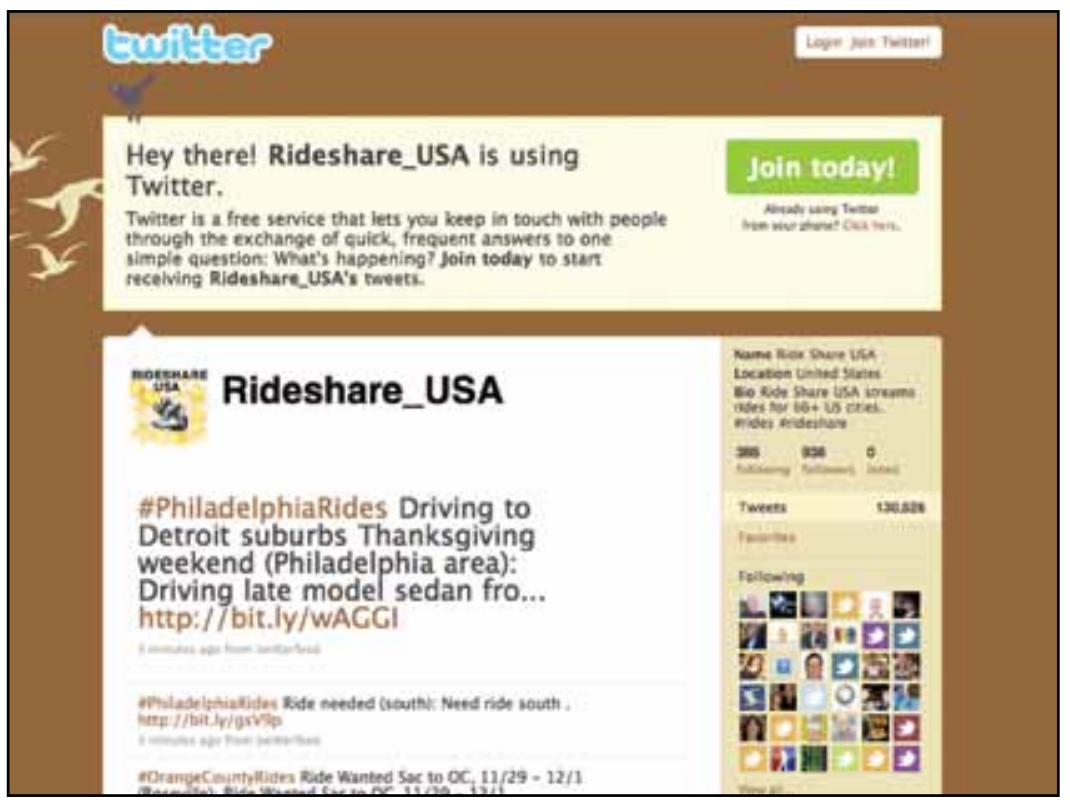

Figure 16: SFBART on Twitter 


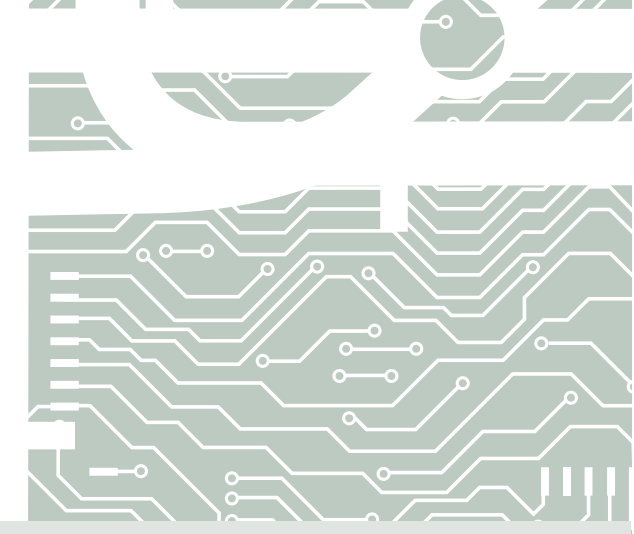

In this chapter

Flickr

Photobucket
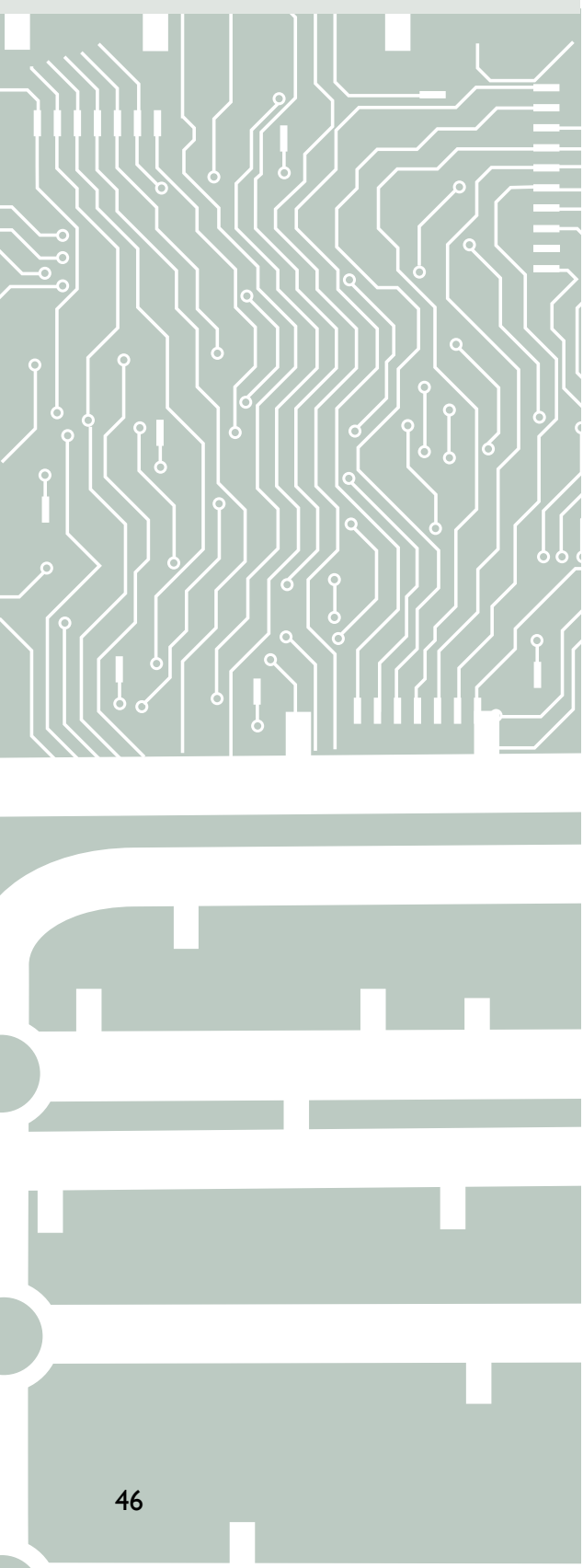

\section{Photo Sharing}

Photo sharing websites allow users to host images on the Internet for little to no cost. These sites allow users to create and edit personalized photo albums, which they can share with others. Most photo sharing websites also allow members to rate and add comments to images.

\section{FLICKR ${ }^{\text {TM }}$}

\section{What is Flickr?}

Flickr is an image and video-sharing website that has been built around the principle of social networking. While Flickr is not the largest photo sharing website, its features and focus on creating communities make it an ideal place to host images. Flickr's basic accounts are free.

\section{Key Terms}

Upload - Upload photos from various sources to the website.

Edit - Flickr has partnered with Picnik ${ }^{\mathrm{TM}}$ to allow photo editing online.

Organize - Use collections, sets, and tags to organize your organization's photos and videos.

$\sim$ Sets: A grouping of photos and videos that are organized around a certain theme. Your organization can use them to highlight its favorite photos and videos, or make an album that is only pictures of your organization's logo, or of photos and videos taken with a particular camera.

Collections: A grouping of sets (or other Collections) so users can organize around grander themes, such as People, Travels, or by year.

Share - Use groups and privacy controls to share your organization's photos and videos.

Geotagging - This allows users to connect their images with a specific area and community. Users can also benefit from searching within an area to find their images.

Keep in Touch - When someone is added as a contact your organization can also choose to add them as either a Friend, Family, or both. Using the "Contacts" page, or by subscribing to a daily email, users are able to keep up to date with what contacts are doing, and vice versa. 
Notes - Users have the option of leaving notes directly on videos and images. Notes only appear when moused over.

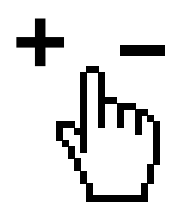

\section{Benefits}

- No cost for image hosting

- Users can see pictures

- Updating daily isn't necessary

- Privacy options allow for pictures to be set with a usage license

- Interactivity allows audience to engage with your organization's content

- Users can add their content about your organization

\section{Drawbacks}

- Free account has monthly limit on file uploads

- Interactivity means that your organization must monitor what users are saying in the comments and notes sections of its pictures and which images are uploaded in the groups

\section{Monitoring}

Flickr Search:This tools allows for the search of pictures and keywords to track and monitor. One can search for artistic, historic, or recent pictures of your organization. One can also track and monitor feedback on both positive and negative images of your organization.

\section{How Can Transit Systems and Commuter Services Organiza- tions Use Flickr ${ }^{\mathrm{TM}}$ ?}

- Post route map artwork

- Post event photos

$\sim$ This allows those who attended to comment or save the pictures they like or appear in

$\sim$ Publicizes past events so that people can look forward to other events in the future

$\sim$ Can be used as part of a PR stunt for branding purposes

Example: Photos of a "Dump the Pump" parade

http:/ /flickr.com/photos/86454591@NO0/161903314/in/photostream/

- Post photos of your transit system

$\sim$ Publicize improvements or additions by taking pictures of new buses or new stops

Example: Photo of a bus sign

http://www.flickr.com/photos/hercwad/3182305568/

Highlight accomplishments of your organization's employees who have a record of great customer service

- Use Geotagging to create awareness

$\sim$ By tagging pictures of your organization's system at a certain location, it can publicize the existence of public transportation in your organization's area to those new to the area or visiting, which encourages them to utilize your transportation system 
Example: Pictures tagged with the word "bus" in Miami, FL http: / / www.flickr.com/places/United+States/Florida/Miami\#bus

- Create a timeline in photographs of your organization's updates and improvements

$\sim$ May appeal to local historians or history buffs to see the timeline of your organization in photos

Example: A group devoted to historical transportation pictures http://www.flickr.com/groups/periodpictures_cars/

- Create a group to allow others to add their pictures of your organization or themselves utilizing your transit system

Example: A group devoted to transportation from around the world http: / /www.flickr.com/groups/transworld2008 /

\section{Example: Dump The Pump}

http: / /flickr.com/photos/86454591@NO0/161903314/in/photostream/

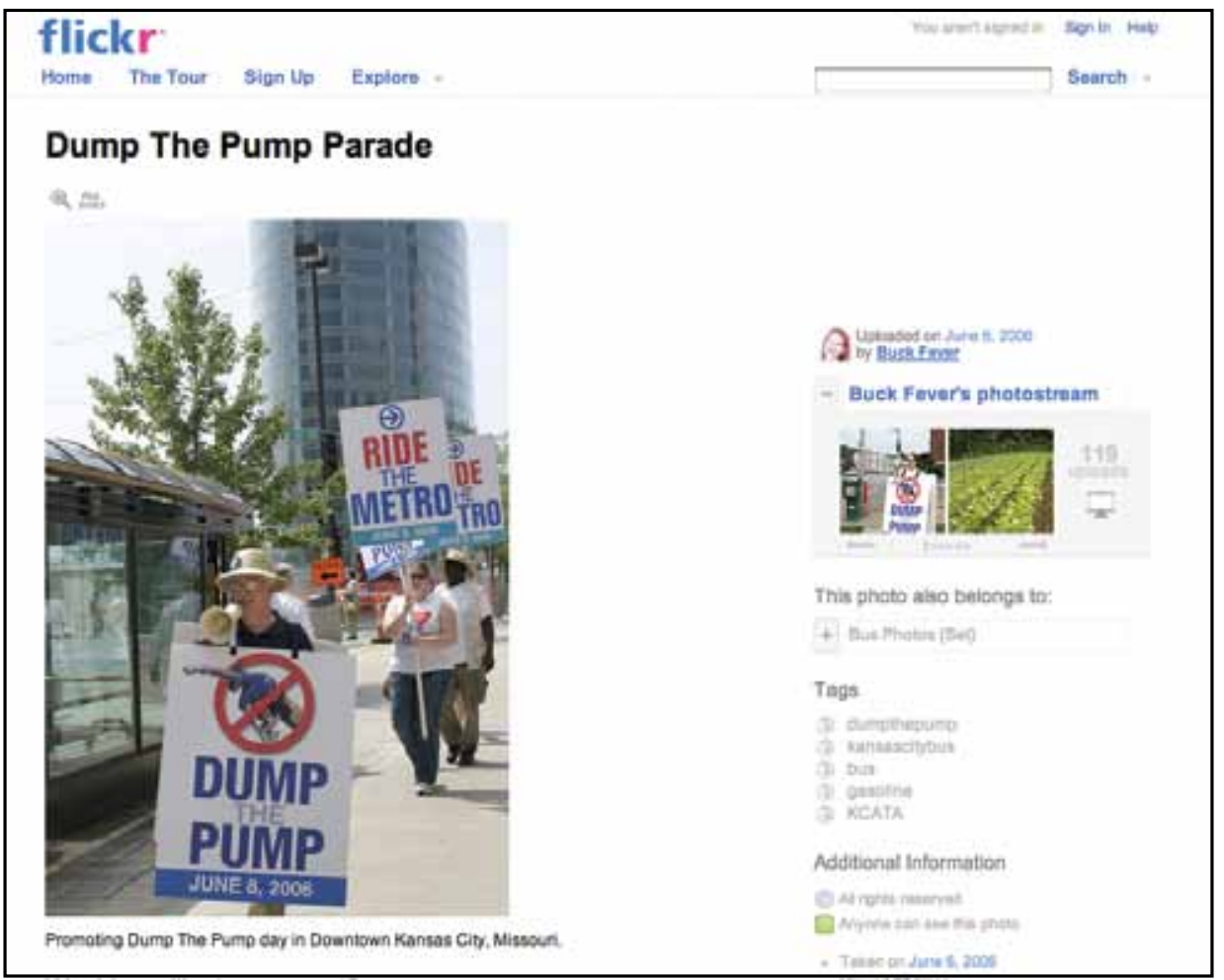

\section{How to Set Up a Flickr Account}

To set up a Flickr account, your organization will need to create a Yahoo $^{\mathrm{TM}}$ account or use an existing Yahoo account. The first step will ask for completion of a profile, which is recommended but not required. Your organization will then need to upload photos and video. It is also important to search for contacts already on Flickr ${ }^{\mathrm{TM}}$.

For more information visit: http: / /www.flickr.com/help/faq/ 


\section{PHOTOBUCKET.COM ${ }^{\mathrm{TM}}$}

\section{What is Photobucket?}

Photobucket is currently the largest photo sharing website on the Internet. Though there are more individual uploads via this platform, it does not include some of the community building tools that Flickr boasts. Users can leave comments on pictures and rate them from $1-5$ stars.

\section{Key Terms}

Group Album - Allows users to collaborate together with friends and family in a single group album of photos and videos.

Scrapbook - Photobucket and Scrapblog ${ }^{\mathrm{TM}}$ have partnered to allow users to combine their photos from Photobucket ${ }^{\mathrm{TM}}$ with themes, stickers, backgrounds, and text to create a scrapbook that can be shared. A scrapbook is very similar to a slideshow, and users can link or share a scrapbook the same way they would link or share any other media in their albums.

Slideshow - Slideshows are a way to display and share multiple images from a user's Photobucket account in a creative way.

Views - This tells users the number of people that have clicked on an image to view it.

Descriptions - A short description to describe the image. These are useful when a picture is not self-explanatory.

Tags - Tagging is a way to define an image as a whole, or it can be used to describe a specific section of an image. These tags aid users when searching for pictures in Photobucket ${ }^{\mathrm{TM}}$.

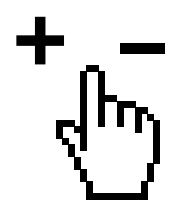

\section{Benefits}

- Users can access the My Photobucket ${ }^{\mathrm{TM}}$ application on Facebook ${ }^{\mathrm{TM}}$ to save time spent on uploading

- Each picture comes with a direct link for easy photo sharing

- If your organization is the "group album owner" then complete control over new content and who contributes is a non-issue

- Other users cannot tag your organization's images

\section{Drawbacks}

- There is no usage license so copyrighted material may be at risk

- The more restricted your organization's group albums are, the less likely people are to participate and engage with the content

- Lack of searching capabilities 


\section{Monitoring}

Photobucket Findstuff ${ }^{\mathrm{TM}}$ is the only way to search for pictures on Photobucket. This search feature allows users to search for images, groups albums, videos, and people based on key words found in the description or tags on a photo.

\section{How Can Transit Systems and Commuter Services Organiza- tions Use Photobucket?}

- Post organization photos

$\sim$ Press event, special festivities, employees pictures, etc.

- Create a group album

$\sim$ Allows users to upload pictures

$\sim$ Allow people within your organization to post pictures of your organization

- Use Photobucket to host images which link to other social media websites or your organization's home page

\section{Example: Perth CAT}

The Central Area Transit bus system allows users to upload personal photos and contribute to the group.

http: / /gs60.photobucket.com/groups/h27/BD72RCPHGJ/

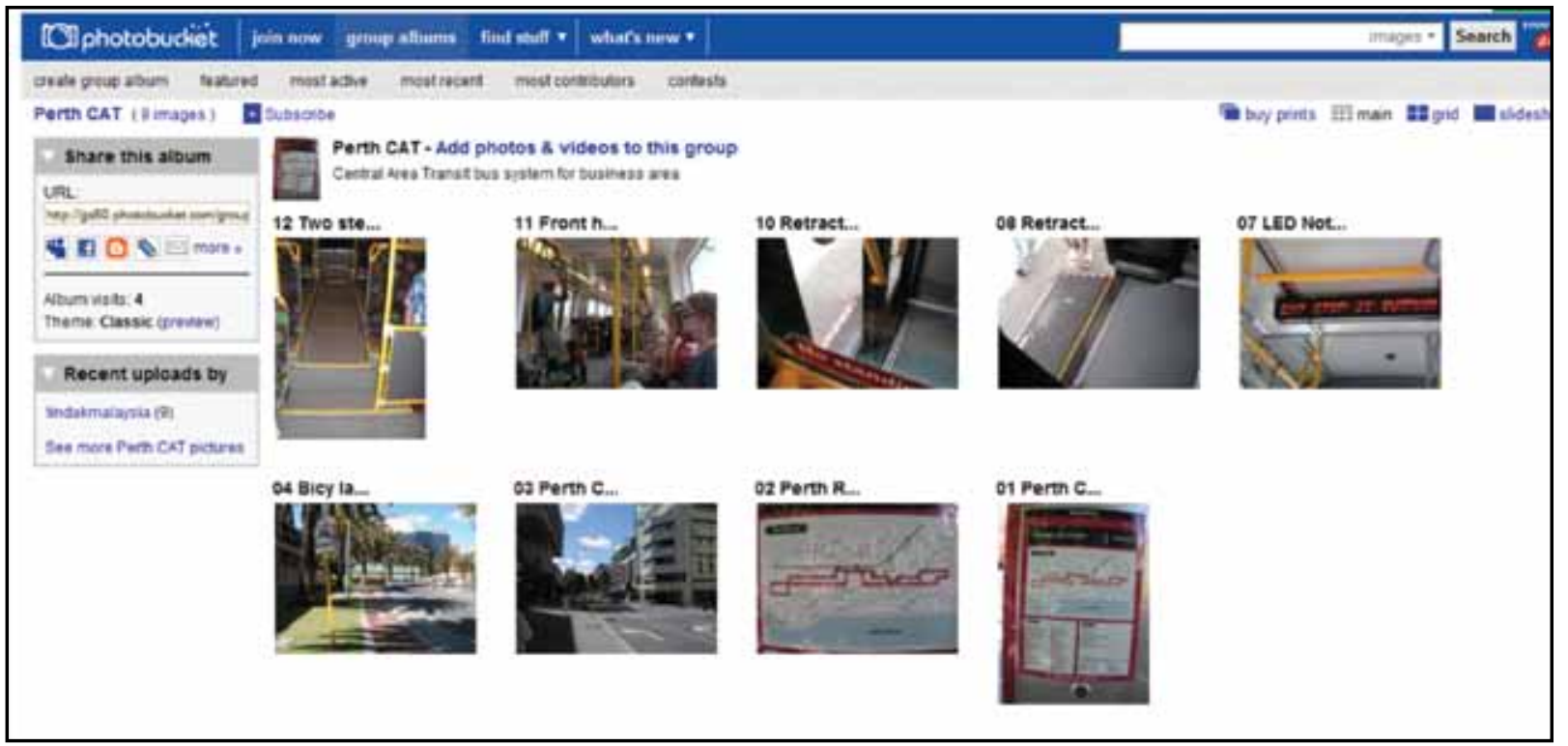

Figure 18: Perth CAT on

Photobucket.com

\section{How to Set Up a Photobucket Account}

To begin using Photobucket simply sign up with a valid email address and start uploading content. For tutorials on setting up and managing your organization's Photobucket account visit http://tutorials.photobucket.com/ 


\section{Video Sharing}

In this chapter

YouTube

Video sharing allows users to host their videos on the Internet for little or no cost. Through these websites, users can post, share, and view others' videos as well. Many of these free services allow members to comment and rank videos of their choice.

\section{YOUTUBE $^{\mathrm{TM}}$}

\section{What is YouTube?}

YouTube is the largest video-sharing website today accounting for nearly 50 percent of all videos viewed on the Internet. Due to YouTube's popularity, it is becoming more frequently used by news organizations as a mass distribution outlet. When a video receives upwards of one million views it is comparable to a highly rated TV show. Anyone can view videos on YouTube, but in order to comment on, rate, or upload a video one must have a YouTube account. Those with accounts will receive video suggestions from the website based on previously watched or rated videos. There are other video hosting websites on the Internet like Vimeo, however, they do not allow for the hosting of business or commercial content.

\section{Key Terms}

Channel - A YouTube user's profile is known as their Channel. All of a user's uploaded videos, favorite videos, fans, and fan comments are viewable from their Channel. Channels are highly customizable allowing the user to change the Channel to fit their specific needs.

Custom Player - Users can design their own embedded video player including adding a name and description, choosing a theme, selecting a layout, and choosing content. Users can then generate embeddable code, which can be used to display YouTube videos on other sites or blogs. 


\section{Monitoring}

YouTube offers extensive monitoring capabilities with an Insight tool.

This allows businesses to track:

- Video Traffic / Views

- Geographic regions of viewers

- Popularity graph

- Discovery tab revealing how users found your organization's video

\section{How Can Transit Systems and Commuter Services Organiza- tions Use YouTube?}

- Create a Channel for brand awareness

$\sim$ Upload current and past video commercials

$\sim$ Upload event video footage

$\sim$ Post rider testimonials

$\sim$ Upload board meetings and other televised events related to transit

- Foster relationships with key stakeholders

$\sim$ Use this platform to facilitate posting of your organization's video blog

$\sim$ Create contests where riders upload videos of their travels

- Host instructional videos for riders

$\sim$ Post how-to footage

- Purchasing a pass, loading bike onto rack, etc.

\section{How to Set Up a YouTube Channel}

To create a YouTube account your organization must either use an existing Google ${ }^{\mathrm{TM}}$ Account or create one. YouTube Channels allows users to fill out a profile and customize their background content. For help getting started visit http://www.youtube.com/t/yt_handbook_home

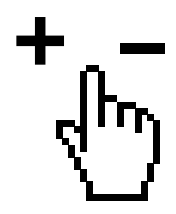

\section{Benefits}

- Creation of a channel allows for brand customization

- The most popular video sharing and viewing site on the internet

- Easy to use and monitor

- Highly customizable

- Users are given suggested videos to watch given their viewing history

\section{Drawbacks}

- Low ratings could deter viewers from watching

-Video responses have potential to bring negative attention to your organization

- Users could take your organization's video and manipulate it for negative purposes 


\section{Example:Washington Metropilitan Area Transit Authority}

Postings of official transit video and commercial footage http:/ / www.youtube.com/user/metroopensdoors

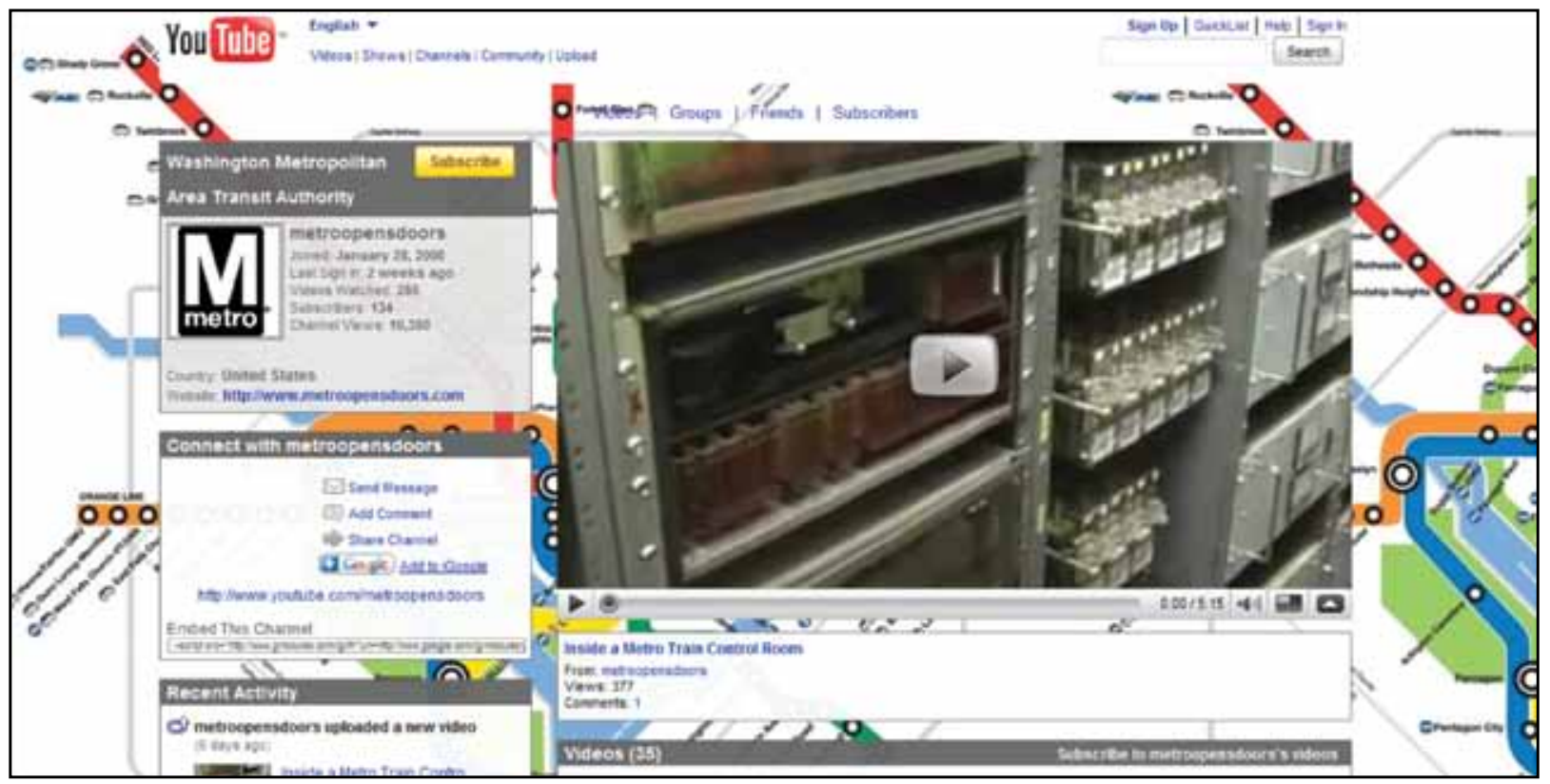

Figure 19:WMATA onYouTube

\section{Example: Hampton Roads Transit}

Rider testimonial video footage uploaded by transit user

http: / / www.youtube.com/watch? $v=\_00 q 51 \mathrm{~W} 8 \mathrm{xmg \& feature=}$ channel_page

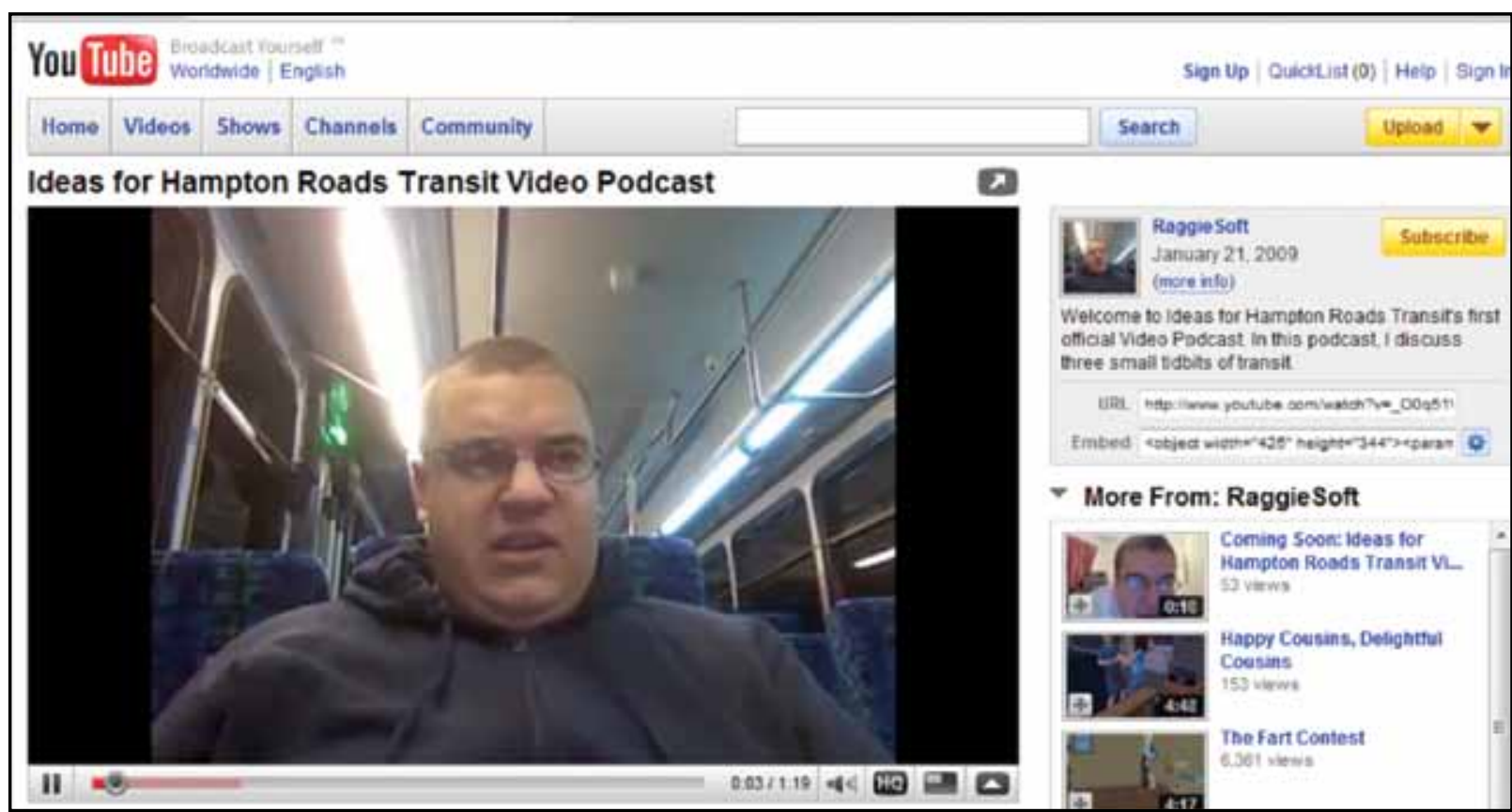

Figure 20: HRT on YouTube 


\section{Example: Carpool UK}

A video podcast where the host carpools with an interesting guest and interviews them along the way.

http: / / www.youtube.com/user/carpoolUK

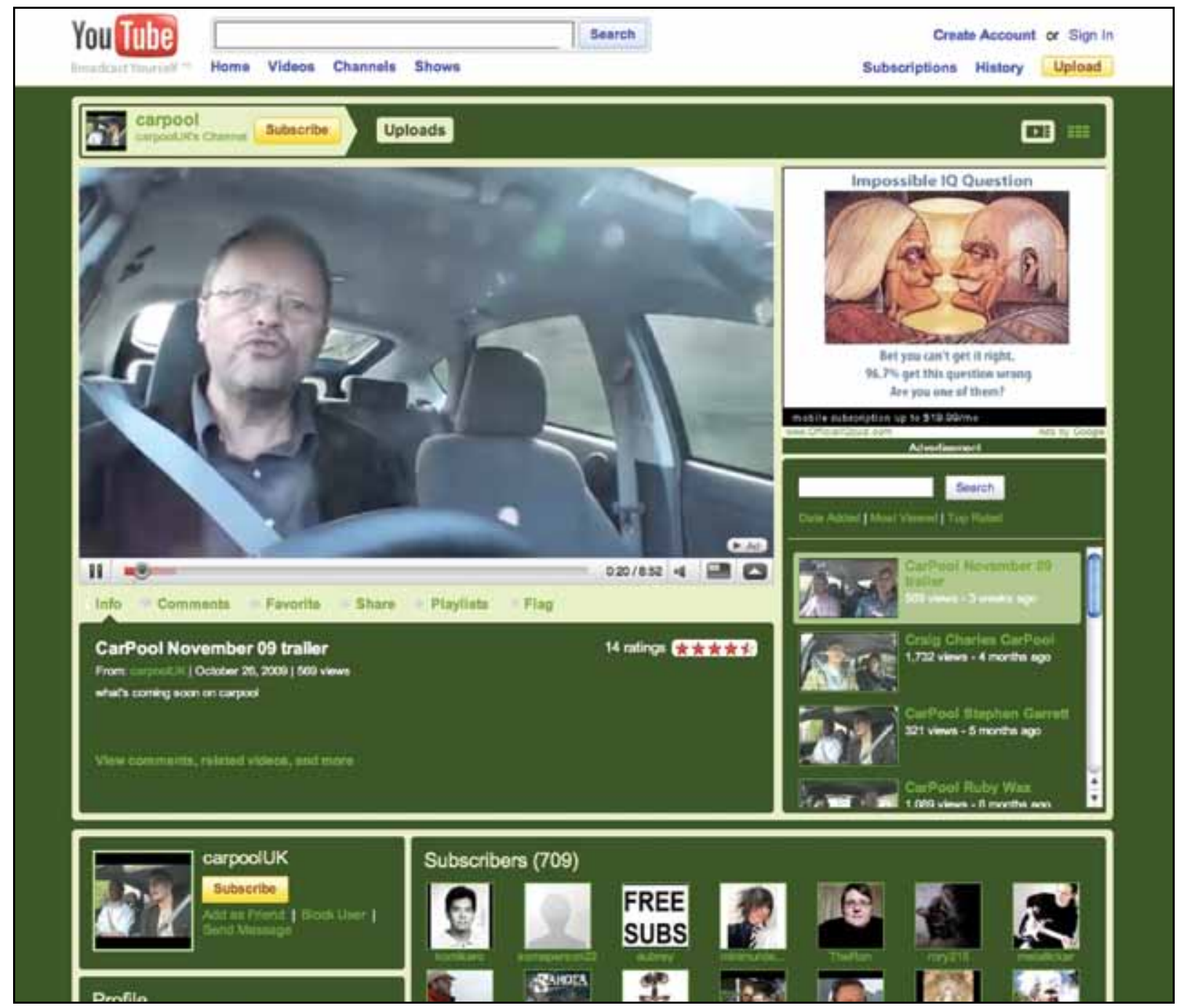

Figure 21: Carpool UK on YouTube 


\section{User-Generated Content}

In this chapter

StumbleUpon

MashUp

Google Transit

Wikipedia

With the increased accessibility and knowledge of technology today, internet users create a wealth of information and multimedia every day. Many websites have taken advantage of this and now allow users to help create, edit, and spread content across the internet. By doing so these websites and applications have a workforce composed of volunteers who help to keep content as up-to-date as possible.

\section{STUMBLEUPON ${ }^{\mathrm{TM}}$}

\section{What is StumbleUpon?}

StumbleUpon is a recommendation engine that recommends web pages, photos, and videos for users to discover and rate. StumbleUpon incorporates peer and social-networking ideas as well as a user's past ratings to suggest new content that may interest them. Users are also able to choose their interests from a list of almost 500 topics.

\section{Key Terms}

Thumbs up (Thumbs down) - This is how users rate the content they "stumble upon.” Users are also able to comment after they rate it.

\section{Monitoring}

The only way to monitor is to regularly check comments left on the link.

\section{How Can Transit Systems and Commuter Services Organizations Use StumbleUpon?}

- Post interesting pictures, videos, or articles about your organization's service, which are entertaining and engaging.

$\sim$ This could be an interesting advertising campaign, video series, etc. 


\section{Example: Link to Bay Area Rapid Transit}

Here Bay Area Rapid Transit has posted entertaining video and links to news releases redirecting viewers to their transportation website. http://www.stumbleupon.com/s/\#1 Ye03N/www.bart.gov//search:transit

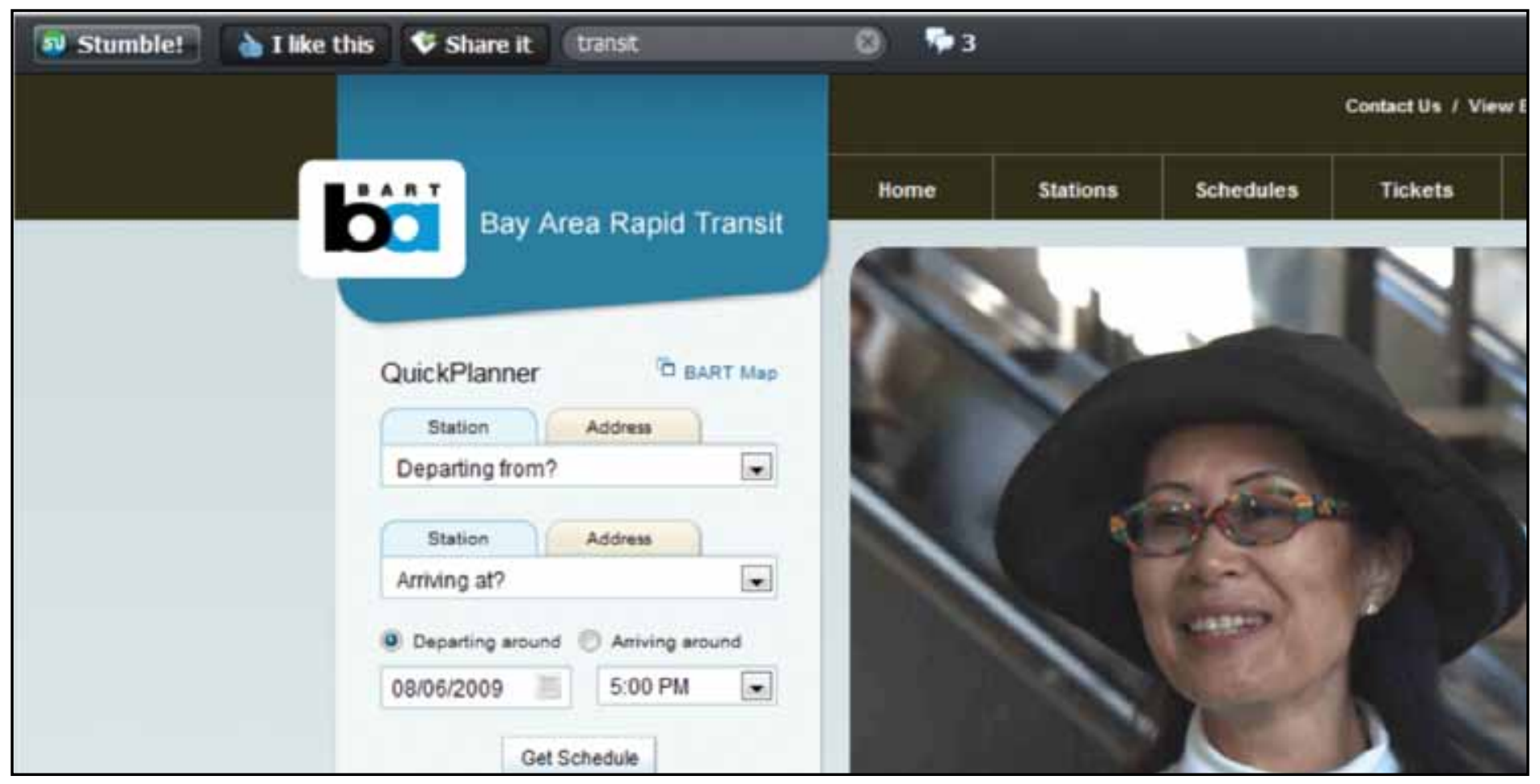

Figure 22: SFBART using

StumbleUpon

\section{How to Use StumbleUpon}

To start adding links to StumbleUpon, your organization must sign up for an account. Your organization will need to fill in a date of birth and a valid email to establish a profile. For more information visit:

http://www.stumbleupon.com/help/How_to_Stumble/

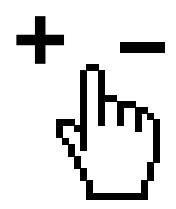

\section{Benefits}

- Increases traffic to website

- Can quickly spread across networks

\section{Drawbacks}

- Content must be very appealing since many may base their ratings on entertainment and visual appeal alone

- Content must be fresh

- Potential for negative review

- No targeting of users

- No real monitoring capabilities 


\section{MASHUP}

\section{What is a MashUp?}

Mashups are the combination of two or more sources of data or functionality to create a new webpage or application. Mashups are created out of a need and often fill in a niche related to a certain geographic area or subject. Simply put, a Mashup is a way to combine two sets of data or information in a visual way. Mashups can be and are created by users all over the world. For instance, a user in Singapore could take data from Tri-Met in Portland and post that to a Mashup website for others to view, use, and create future Mashups. In this way, Google is providing a platform by which innovation, advancement, and creativity can be expressed by individuals from all nations and walks of life. Ultimately, this can be a benefit to transit agencies and commuter services organizations that make data available to the public platform.

Google offers the Google App Engine ${ }^{\mathrm{TM}}$ wherein programmers can create Mashups and other apps. The Google App Engine is free, but does include restrictions on storage, bandwidth, or CPU cycles required by the application.

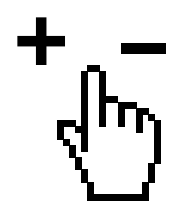

\section{Benefits}

- Customized data

- High usability

- Your organization controls what data is released to the public

\section{Drawbacks}

- Must have knowledge of programming languages

- Upkeep of information takes time

-Your organization must troubleshoot and update the program or app to maintain a functional Mashup

- Your organization has no control over how data released to the public will be used

\section{Monitoring}

Mashups are most often either an application or a webpage, therefore they can be monitored by hits to their respective website.

\section{How Can Transit Systems and Commuter Services Organizations Use StumbleUpon?}

- Integrate into a pre-existing mashup tool such as Google Transit ${ }^{\mathrm{TM}}$

- Creation of transit specific mashup application

$\sim$ Could track national ridership visually by comparison

$\sim$ Could provide an online platform for transit riders to communicate and have their specific location charted 


\section{Example: Carpool Mashup Matchmaker}

This Mashup uses Google maps along with other information to help users find carpools that fit their personal preferences and allows them to officially join those carpools. Users can also create a carpool.

http: / / www.appsfordemocracy.org/carpool-mashup-matchmaker /

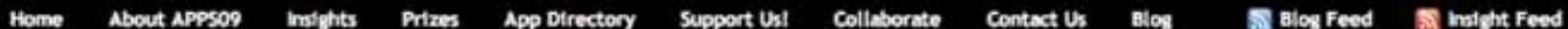

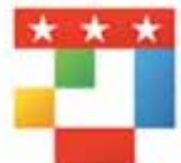
Apps for Democracy Community Edition

for the

\section{Carpool Mashup Matchmaker $\mid$ Conments $\mid \begin{aligned} & 2008 \\ & \text { November 12th }\end{aligned}$} 764

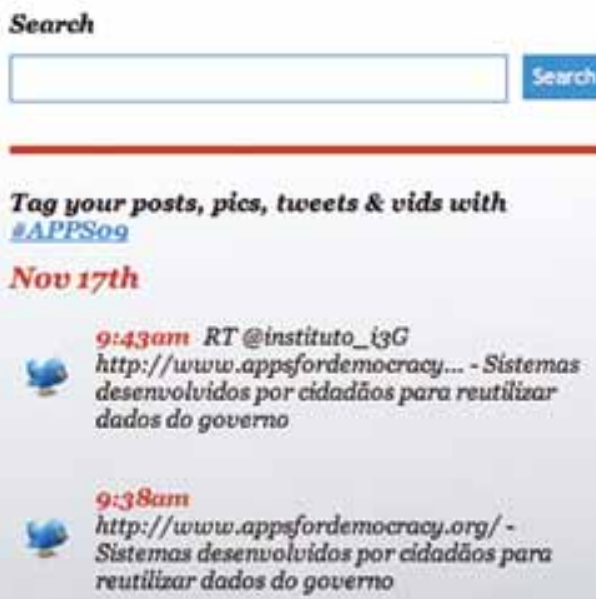

Nov 12th

Btriam @ieffsonderman ala Apps for Democracy in Woshington DC-I am working on trying to replicate some of that for USEPA

agency sitrs smouncementi Appos aute aWards tout bronze crime fucobse Google Maps hum honorablemention

Figure 23: Carpool Mashup

Matchmaker 


\section{GOOGLE TRANSIT}

\section{What is Google Transit?}

Google Transit is one of the most widely known and used Mashups. This Google trip planning service calculates public transportation routes, time, and cost, and can compare the trip to someone using a car. Users can receive step-by-step transit directions in the web browser or on a mobile phone, find transit stops in their area or view station information and schedules.

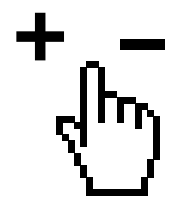

\section{Benefits}

- Riders can discover new routes

- Free for both organizations and users

- Publicizes your organization on a widelyused mapping service

- Connects neighboring agencies data to improve inter-agency connectivity

\section{Drawbacks}

- Information controlled by Google Transit

- Process of uploading transit information can be cumbersome

\section{How Can Transit Systems and Commuter Services Organizations Use Google Transit?}

- Upload route information, along with maps of the coverage area to lead users to stops.

$\sim$ Specific directions for this process can be found here:

http://maps.google.com/help/maps/transit/partners/participate.html

\section{Florida systems currently uploaded:}

Miami-Dade Transit, Broward County Transit, Tampa (HART), Pinellas County

\section{How to Use Google Transit}

The process of signing up your organization for Google Transit can be cumbersome, as it requires detailed GPS coordinate uploads. To begin this process, your organization must sign up for the Google Transit Partners program, and follow their process for creating a data feed. To learn more visit http://maps.google.com/help/maps/transit/partners/participate.html 


\section{WIKIPEDIA ${ }^{\circledR}$}

\section{What is Wikipedia?}

Wikipedia is a free, user-edited online encyclopedia that anyone can search and read. Wikipedia volunteers add and edit content on the site and use citations, external links, and references to validate their edits and additions. Wikipedia is monitored to remove or correct editorial errors made by users.

\section{Key Terms}

Semi-protection - Allows only registered users to edit the article. Popular pages may need this in order to protect from vandalism.

Community Portal - This page is where users can find out what is happening on Wikipedia, learn what tasks need to be done, what groups there are to join, and share news about events or activities on Wikipedia.

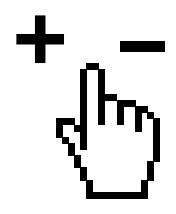

\section{Benefits}

- Audience seeks your organization's information

- All major search engines use Wikipedia as one of the top search returns

\section{Drawbacks}

- Often seen as an unreliable source of information

- Consumers can express discontent or incorrect information until it is edited

- No control over information after it is disseminated

- Knowledge of Wikipedia's programming language is needed

\section{Monitoring}

Stats.grok.se is a third-party site that manages a page-hit counter for Wikipedia. Users can enter the name of the article they would like to monitor and the page retrieves the number of hits on the article. Users can also click on the Top option and the 1000 most viewed pages for the entered subject will appear. 


\section{How Can Transit Systems and Commuter Services Organizations Use Wikipedia?}

- Information Center

$\sim$ Post route information, organization profile, service times, fares and more

\section{Example:TransIT}

This transit service in Fredrick County, Maryland lists information on fares, bus fleet, and routes.

http:/ / en.wikipedia.org/wiki / TransIT

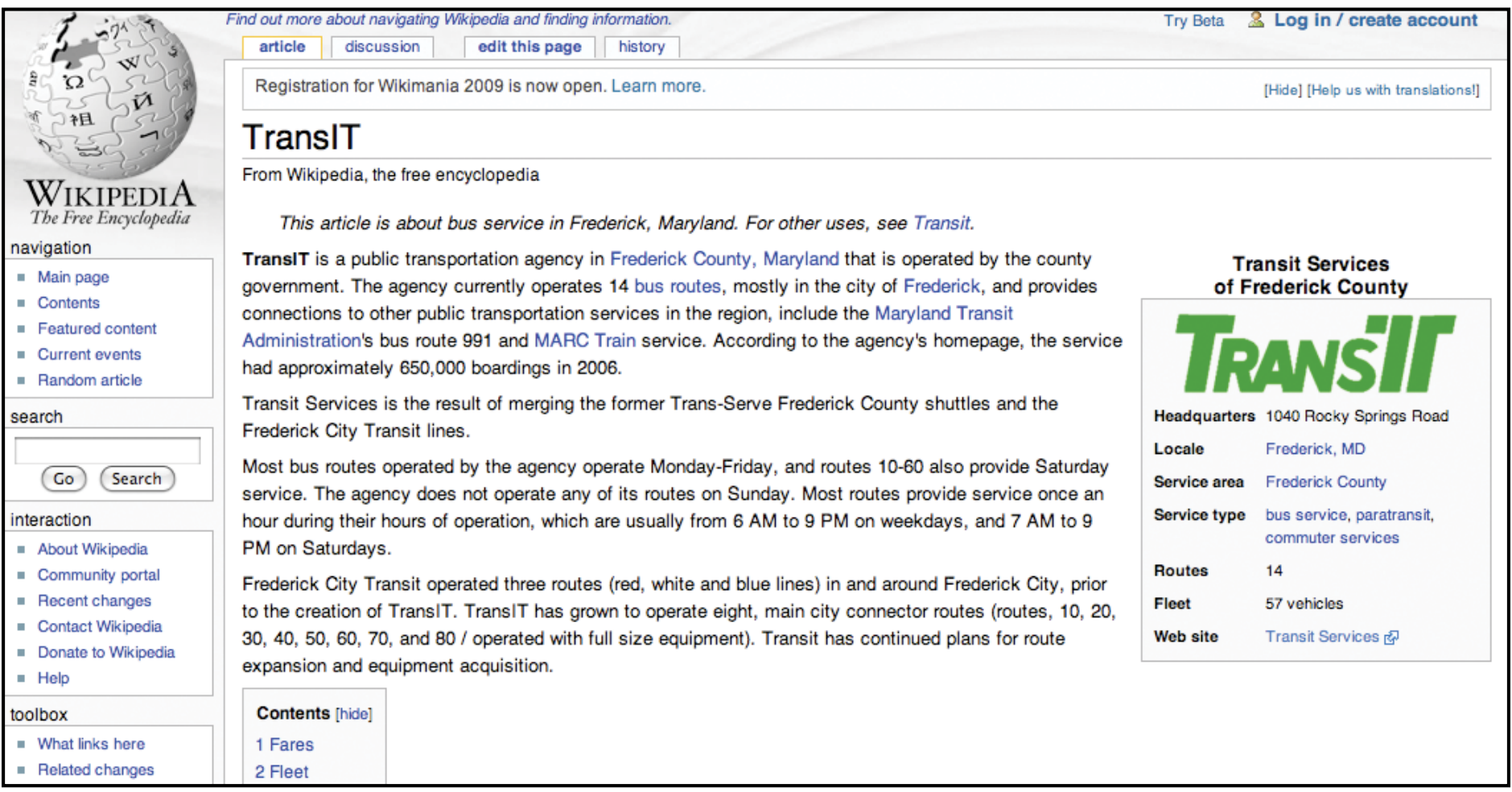

Figure 24:TransIT on Wikipedia

\section{How to Create or Edit a Wikipedia Article}

To create and edit articles on Wikipedia, your organization must create an account and use Wikipedia's programming language. For more information visit: http: / / en.wikipedia.org/wiki/Wikipedia:Introduction_2 


\section{Mobile Web}

\section{What is Mobile Web?}

Mobile Web is the term used when the Internet is accessed via a cell phone, PDA, or other device with Internet capabilities (such as the Sony PSP ${ }^{\mathrm{TM}}$ or the Apple iPod Touch ${ }^{\mathrm{TM}}$ ). With the introduction of new phones and increasing technological capabilities, mobile web use in the United States has grown to over 95 million users in 2008. Becuase of this extensive growth, it is advantageous to transit agencies and commuter services organizations to utilize mobile web and its applications to reach consumers. Transit operations are always in real time. Mobile web users can always communicate in real time. Get the picture?

\section{Key Terms}

Smartphone - A cell phone that includes advanced features. Though there are no set standards, most smartphones include: an operating system, Internet browsing capabilities, a camera, and the ability to send and receive email.

$3 G$ - A set of standards for high-speed wireless communication. This is the current standard for speed and security of wireless networks and is available in most areas.

Application (App) - The software programs that can be uploaded onto smartphones in order to run programs.

Blackberry $^{\circledR}$ - The Blackberry line of smartphones is the most popular line today. These phones are typically viewed as the choice for business professionals. They are largely focused on increasing ease of communication.

${ }^{i}$ Phone ${ }^{\mathrm{TM}}$ - The iPhone line of smartphones is the second most popular today. They include a database of Apps accessible from iTunes, which allows users to download third-party programs onto their iPhone.

\section{Monitoring}

Monitoring can be established upon tracking the number of downloads from a particular application or the number of hits to a specific web page. 


\section{How Can Transit Systems and Commuter Services Organizations Use Mobile Web?}

- Keep riders up-to-date on route delays, route times, and changes in routes via a mobile website or phone app.

\section{Examples:}

- Mobile Website

$\sim$ Flight Stats ${ }^{\mathrm{TM}}$ is a website that provides flight tracking for airlines and airports, including live flight status, estimated arrival and departure times, delays, airport weather, real-time cancellation data, and flight alerts. Flight Stats also has a mobile website which allows users on mobile devices to track this information. http:/ / mobile.flightstats.com

$\sim \mathrm{Me}^{\mathrm{Bus}}{ }^{\mathrm{TM}}$ and Me2Sub ${ }^{\mathrm{TM}}: \mathrm{Me} 2 \mathrm{Bus}$ is a mobile website optimized for iPhone users. The website allows users to search for their bus route and find out how long before it arrives at a specific stop. Me2Sub includes the same information for subway stops. Both websites only offer information for a limited number of cities at this time. http://me2bus.com/ and http://me2sub.com

- Applications

$\sim$ iTrans ${ }^{\mathrm{TM}}$ is an iPhone app that allows users to enter their starting location and destination and it finds the fastest routes at that time. iTrans also includes schedules, maps, and advisories on delays. http://itrans.info /

$\sim$ NYC Transit $^{\mathrm{TM}}$ is an application for Blackberry phones. It includes information on the following routes: Metro North train, NJ Transit train and bus, and NY Waterway ferry schedules. The application downloads all information onto a user's phone and is therefore usable even when users do not have a signal. http:/ / www.blackberrysites.com/?p=2406

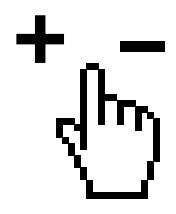

\section{Benefits}

- Increased accessibility of route information

- Ability to customize for the mobile experience - add only content important to users on the move

- Ability to use real-time GPS information to help users find nearby routes

- Complete control of information displayed

\section{Drawbacks}

- Small screen size

- Can be difficult to navigate

- Regular web pages do not display well on all mobile browsers 


\section{Social Media Wrap-up}

\section{WE HAVE A WEBSITE, SO WHAT?}

Social media has proven to be a powerful and cost-effective communication tool for many organizations across the globe. It is important to point out, however, that though all outlets presented in this guidebook are free to join, they do have significant time considerations. For many, time is money. Social media is a dynamic field that requires constant research and monitoring and cannot be relegated solely to normal business hours. As such, your agency must be ready to respond at any time.

Today, even many traditional outlets are tapping into social media tools to broadcast consumer news. Front page stories, radio interviews, and television programming is being built around consumer-generated content. Why? These tools give full and direct access to their target audiences. What's more, these tools allow them not only to push information outward, but interact with their users throughout the process.

In this sense, anyone with a computer and content can become an instant journalist. Certainly with interaction and consumer-generated information, comes risk. Many organizations are fearful of losing control over their brand and message. However, consumers and end-users can affect and discuss your brand via these social media outlets regardless of whether you have an account or not. Ignorance is not bliss.

Specifically for transit or commuter organizations, the constant motion of activity engenders the unique need to keep users up-to-date. These new media platforms allow for more personalized real-time communication that can yield results such as increased ridership, awareness, and community support from stakeholders. One of the key benefits of social media as a communication tool is its flexibility. These tools have the ability to take on many shapes and sizes depending on your organizational goals and needs. Social media can be used as a PR tool not only for promoting events and updates, but also for crisis control and prevention. It gives your agency the opportunity to frame a story and release all of the applicable facts to the public before traditional media has an opportunity to broadcast the news.

Social media can also be used as a marketing tool helping to engage, educate, and inform users about the services their local public transit agencies offer. Engaging users online can foster a positive relationship 
between your organization and potential consumers. The personalized nature of social media can result in strengthened community partnerships and outreach. If your efforts are successful, this positive experience will encourage those same users to utilize public transit.

Social media can also be used as a customer relations tool, where the efforts of transit call centers can also be devoted to monitoring and responding to customers via social media. Often times, users are more apt to complain about an issue using a social media tool than they would via phone call or letter. By monitoring keywords, your organization will be able to respond to complaints you were previously unaware of, and preempt backlash that could grow from a user's negative experience.

All organizations are encouraged to listen as a first step. Observe the activity on these social media outlets to see what people are saying. This will enable you to begin understanding the types of conversations happening amongst your target audience, and the need for a response. One of the most frequent questions encountered during this project was, "What if someone says something negative about your organization? This is such a public and visible platform.”The response:

1) People have the ability to talk negatively about your organization right now, whether you're listening or not and regardless of whether you even have an account set up.

2) Given that it's a visible platform, your organization has the opportunity to respond in a very public way - and potentially alter the opinion of not just the individual who made the negative comment, but all those watching. Prior to development of these online tools, organizations would receive hand-written letters, phone calls, or in-person complaints. Many still do. These channels of communication are not vanishing. However, online conversations need to be considered and evaluated in the same manner.

Connecting with consumers means your organization must evaluate and understand where they are communicating. By turning a blind eye to these online tools, your organization risks overlooking key segments of the population. In fact, larger transit agencies who are leading the way in social media have found that by incorporating online tools with more traditional media, they have been successful in growing overall system ridership. A great example of this is the Redwood Transit System, which posted a more than 40 percent increase in ridership 
after uploading route information to Google Transit. As Jim Allison from BART recently said in a Youtube ${ }^{\mathrm{TM}}$ video sponsored by the Federal Transit Administration, "San Francisco I think is now where maybe the rest of the country will be in just a few years... While we may be ahead of the curve, I don't think we are riding a flash in the pan here."

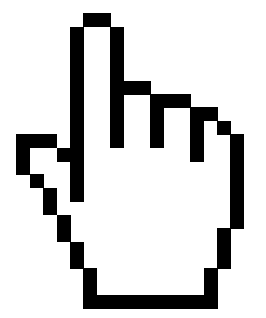

